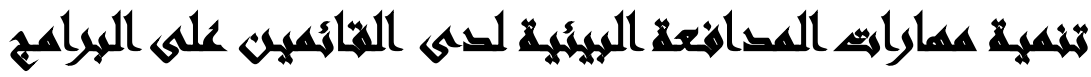 هيك الإياعة المسرية
}

[17]

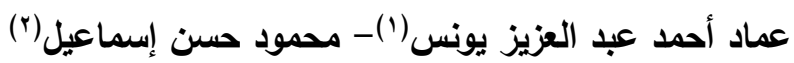

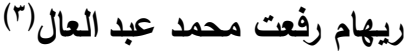

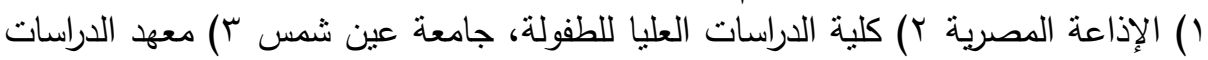

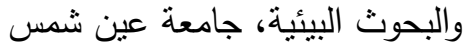

\section{coll}

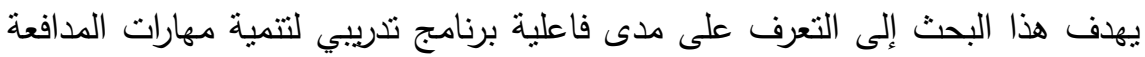

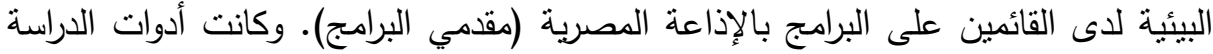
كما يلي: مقياس مهارات بيئية (بطاقة ملاحظة بيئية)، برنامج تدريبية الإدائي متعدد الأنشطة البيائية. وقام الباحثون بتحديد أربعة أبعاد لمقياس المهارات البيئية معتمداً على الدراسات السابقة والدراسة الاستطلاعية.

وقد أظهر التحليل الإحصائي لنتائج مقياس المهارات صحة الفروض وفائلة الفاعلية البرنامج

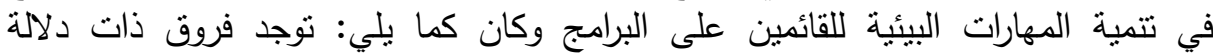

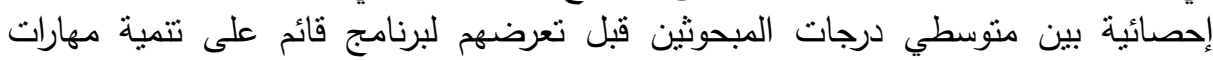

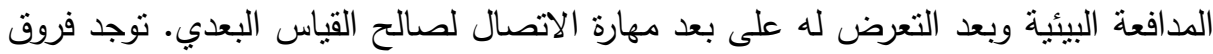

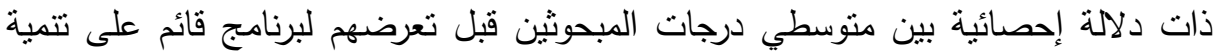

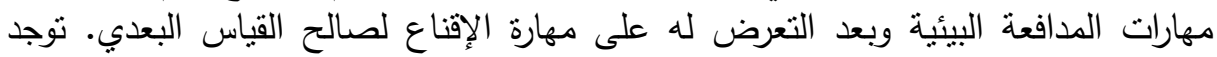

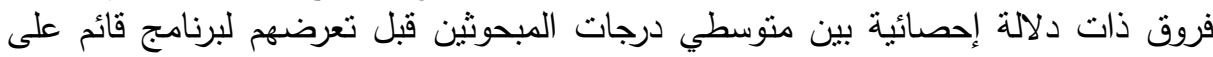

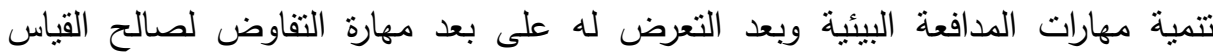

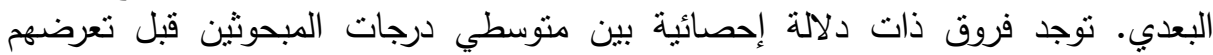

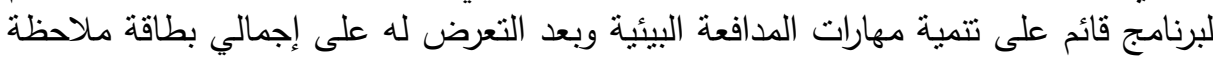
مهارات المدافعة البيئية لصالح القياس البعدي. لماري. 


\section{8atill}

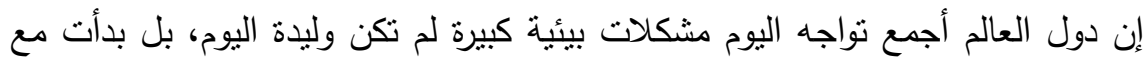

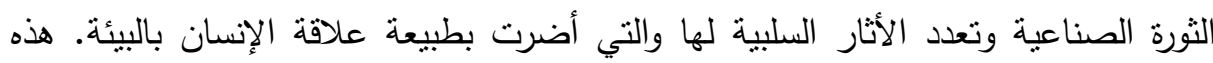

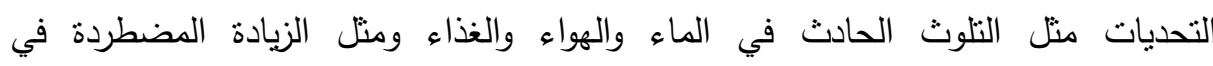
النموالسكاني وانتشار المخلفات المختلفة والأثار المحتملة للتغيرات المناخية المتسارعة. لذاء واء الذاء كان على الدول وضع وتطبيق السياسات والبرامج والإجراءات التي تؤدي إلى دمج البعد البيئي في كافة القطاعات التتموية وتعزيز مشاركة المجتمع المدني في العديد من مجالات التوعية

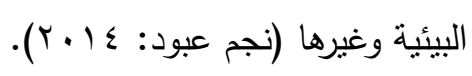

ولما كانت التوعية البيئية للمواطنين من أهم القضايا التي دعت إليها الميأ المؤتمرات الدولية

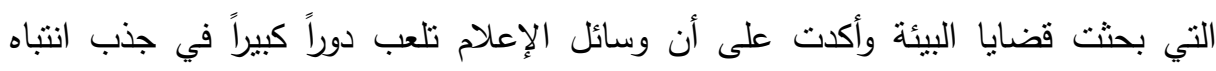
الجمهور وتوجيه اهتمامه لقضية معينة، بما يميزها عن غيرها من حيث سرعة الانتشار وقدرتها على التأثير والاقناع. (مصطفى كمال طلبة: . 99 ())، (Judy Z. Segal (1991).

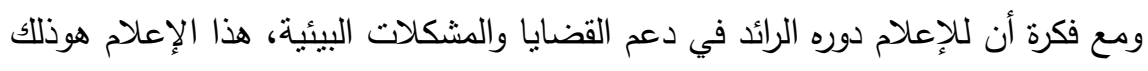

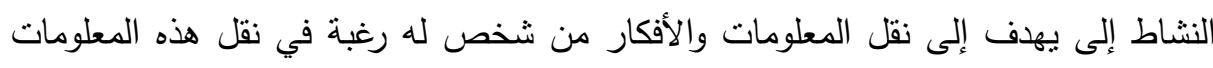
(الإعلامي) إلى شخص آخر (المستمع) بهدف إحاطته علمًا بها. (عبد الفتاح عبد النبي:

وتعتبر الإذاعة من أهم وسائل الإعلام التي تمنلك إمكانيات هائلة يمكن استغلالها في

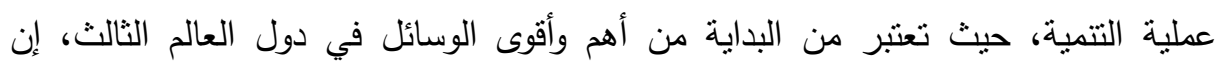

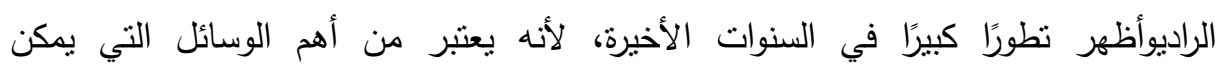

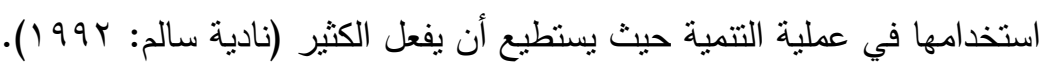

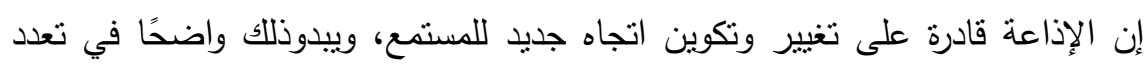
برامجها الثقافية والدينية والأغاني والموسيقى وغيرها، وتوظيف تلإدك الأثكال لخدمة البيئة، مما يؤدي إلى تعاظم دور الإذاعة السمعية في التوجه الذي برمي إلى تعريف العالم بالمشاكل

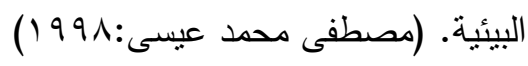




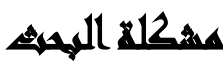

إن الاهتمام العالمي بدور الإعلام في مواجهة القضايا البيئة وأهمية إعداد القائمين

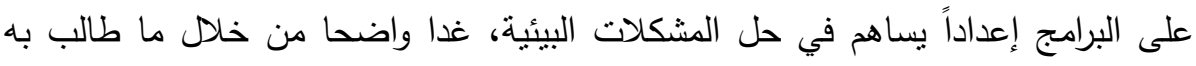
إعلان نواكثوط الصادر عن المؤتمر الإقلامي الثاني لثبكة الإعلاميين الأفارقة للبيئة

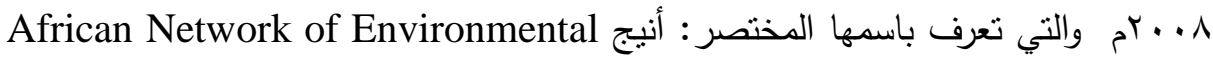
والتي تعمل تحت مظلة الأمم المتحدة، وقد نادى المؤتمر إلى تفعيل دور (Journalist) الإعلام في قضايا البيئة في القارة الأفريقية وتدريب الكوادر الإعلامية على مهارات المدافعة

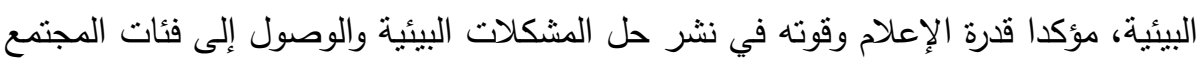
كافة: الحكومات والقطاع الخاص والمجتمع المدني والجمعيات الأهلية والعلماء (أنيج ^ ـ. . ؟). من أجل ذلك قام الباحث عمل دراسة استطلاعية (استبيان) مع عدد من مقدمي البرامج للتعرف على معرفتهم للمدافعة البيئية ومدى امتلاكهم لبعض مهاراتها واستخدامها في

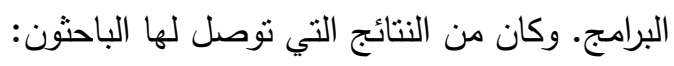

• لم يتعرف العديد من مقدمي البرامج على مفهوم المدافعة البيئية ومهاراتها.

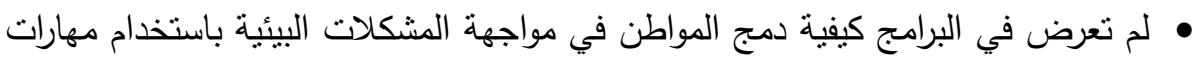
المدافعة المناسبة في البرامج الإذاعية. على رغم من نتاول البرامج الإذاعية للكثير من المشكلات البيئية إلا أن معالجتها اقتصرث

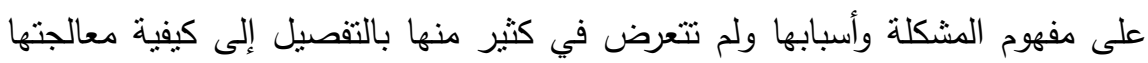
أومواجهنها.

\section{أسريلا المهيه}

السؤال الرئيس للبحث "ما فاعلية برنامج في تتمية مهارات المدافعة البيئية لدى القائمين

على البرامج بالإذاعة المصرية؟" ويتطلب ذلك التعرف على الأسئلة التالية: • ما مهارات المدافعة البيئية التي ينبغي تتميتها لمقدمي البرامج الإذاعية؟ الإديه

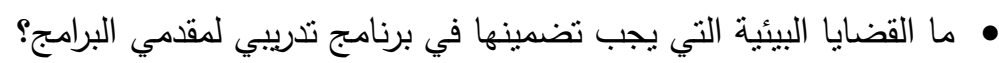

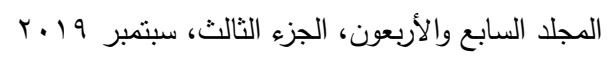




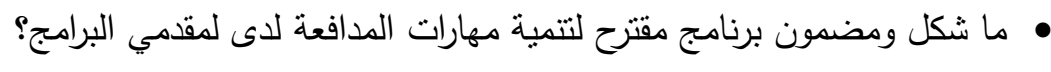

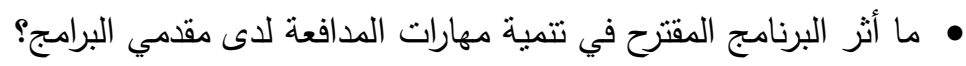

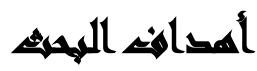

1-تعرُف واقع المدافعة البيئية ومهاراتها لدى مقدمي البرامج بالإذاعة المصرية. r-تتمية الوعي وكسب اهتمام مقدمي البرامج الإذاعية بالبيئة. r- إكساب مهارات المدافعة البيئية لمقدمي البرامج الإذاعية.

ع-تصميم وبناء برنامج مقترح لإكساب مهارات المدافعة البيئية لمقدمي البرامج الإذاعية لئية.

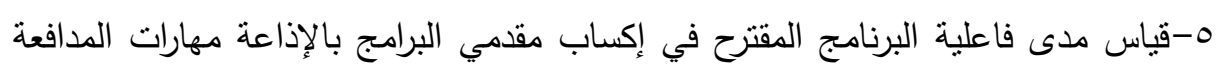
البيئية.

\section{هزور التواسمة}

توجد فروق ذات دلالة إحصائية بين متوسطي درجات الإعلاميين قبل تعرضهم لبرنامج

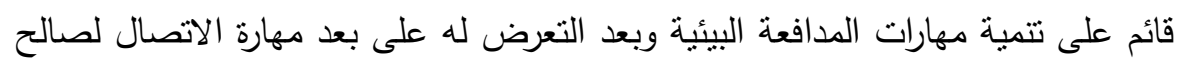
القياس البعدي. • توجد فروق ذات دلالة إحصائية بين منوسطي درجات الإعلاميين قبل تعرضهم لبرنامج

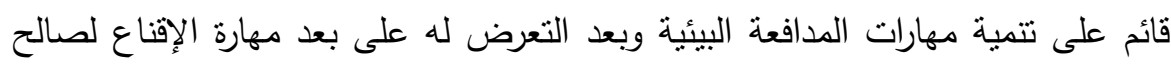
القياس البعدي. • توجد فروق ذات دلالة إحصائية بين منوسطي درجات الإعلاميين قبل تعرضهم لبرنامج

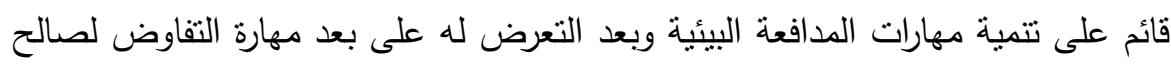
القياس البعدي. • توجد فروق ذات دلالة إحصائية بين منوسطي درجات الإعلاميين قبل تعرضهم لبرنامج

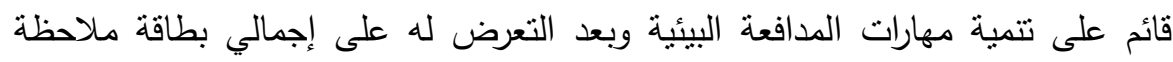
مهارات المدافعة البيئية لصالح القياس البعدي. 


\section{أهمية التواسمة}

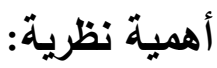

• تتمية الوعي وكسب اهتمام القائمين على البرامج الإذاعية بالبيئة. • توجيه اهتمام القائمين على الإعلام نحوأهمية دمج الددافعة البيئية ومهاراتها إلى البرامج التئة الإذاعية. • تقديم قائمة بمهارات المدافعة البيئية التي يجب تتميتها لدى القائمين بالبرامج في الإذاعة

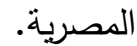

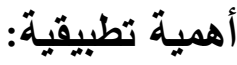
مقام برنامج تدريبي لتتمية مهارات الدافعة البيئية لرفع كفاءة القائمين بالبرامج في

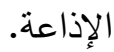
• يُمَكَن العديد من الفئات من ممارسة مهارات المدافعة البيئية واكتسابها مثل: مقدمي البرامج بالإذاعة المصرية، معدي البرامج بالإذاعة المصرية، الصحفيين، مسئولي الإدارات

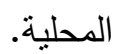

\section{هبوض التواسم}

الحدود البشرية: مقدمي البرامج في الثبكات الإذاعية المختلفة: البرنامج العام - القرآن

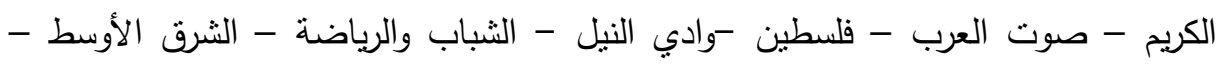
القاهرة الكبرى - الثبكة الثقافية - شبكة الموجهات(العبري) (· ب مقدم ومقدمة).

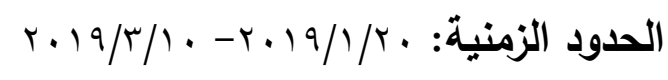
الحدود المكانية: مبنى اتحاد الإذاعة والتلايفزيون بماسبيرو، القاهرة. 


\section{كمطلحايت الصراسهة}

المهارة: أنها القدرة على القيام بالأعمال الأدائية المعقدة بسهولة وإنقان وسرعة وفق سلسلة

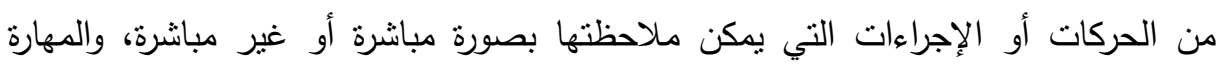

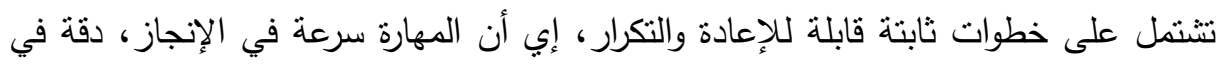

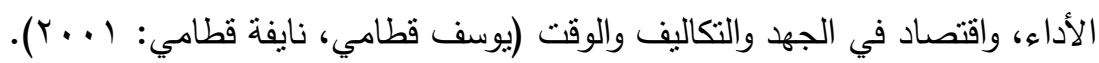

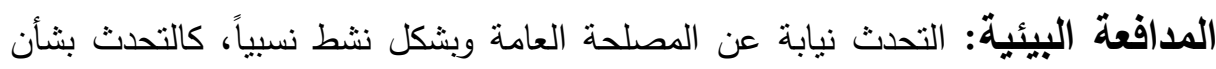

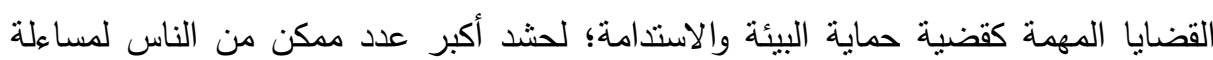

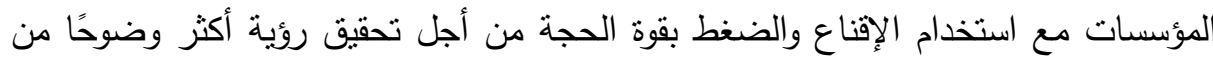

أجل الصالح العام (Steve Chase: 2006). كما عرفها ديك دي يونج بأنها العمل من أجل إيجاد الحجج والبراهين لإقتاع القادة العاد العاد

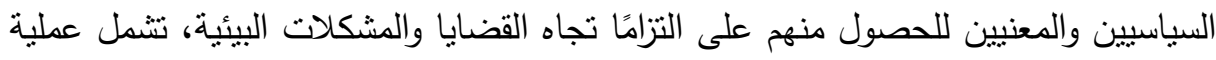

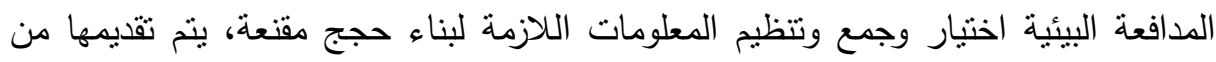

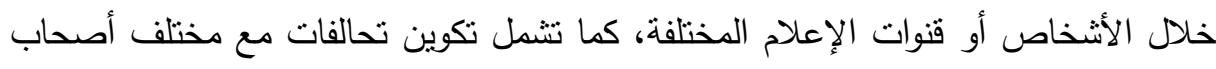

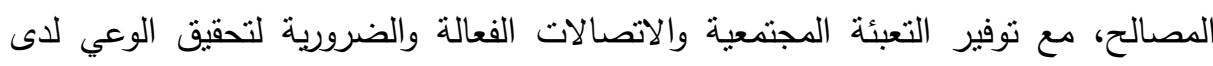
المجتمع وكسب التزام من صناع القرار تجاه قضايا البيئة. (Dick de Jong: 2003 ).

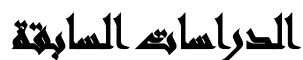

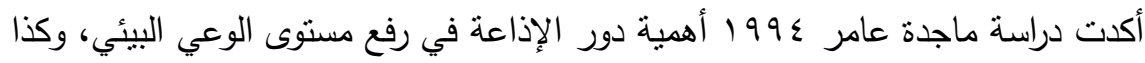

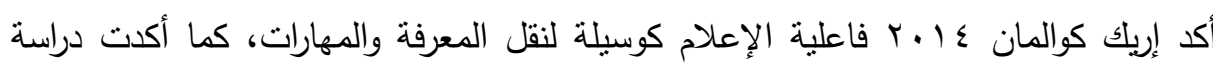

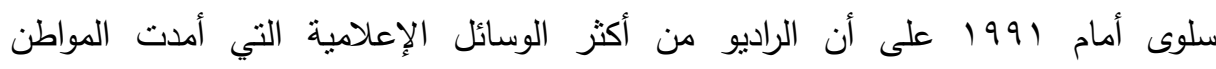

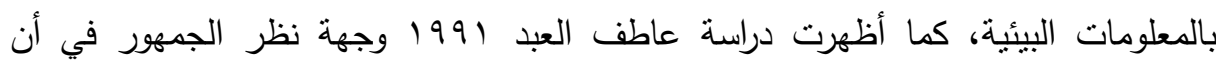

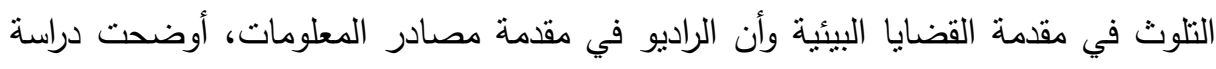

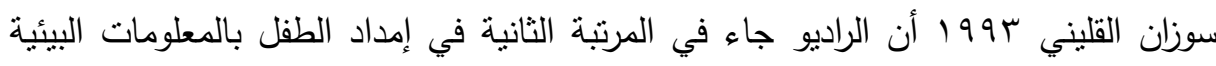

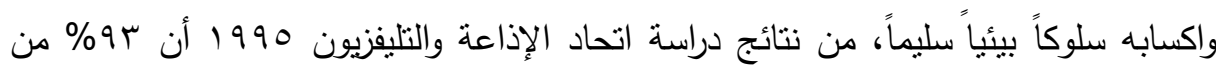


عينة عشوائية (· . M مفردة) تمثل عشر محافظات يستمعون لبرامج إذاعية تقدم معلومات

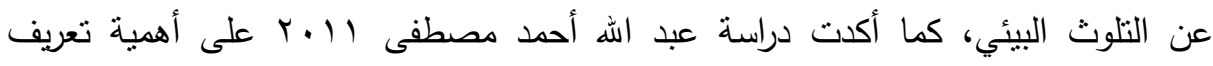

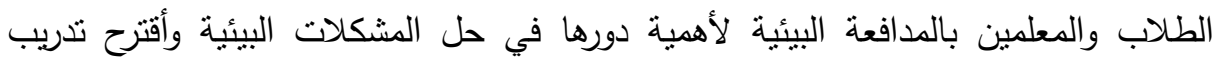
الفئات ذات الصلة بالثأن العام.

\section{الإبطار المعرهيم}

أن ظهور المشكلات البيئية نتج بسبب عدم وعي الإنسان وسلوكياته السلبية، وأن تربية الإنسان تربية بيئية قد تمكنه من المساهمة في حل مثل هذه المشكلات، وأن امتلاكه المعرفة

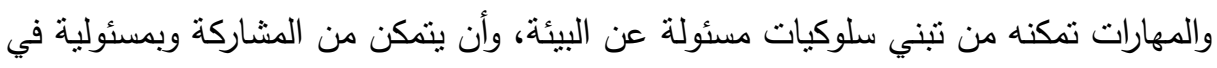
اصدار القرارات التي تحسن من البيئة (Rolston III, H: 1997). إن قيام المواطنين فرادى وجماعات في دعم حماية البيئة المحيطة تحدثاً أو كتابة أو لون الئه

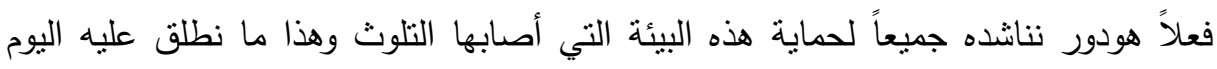

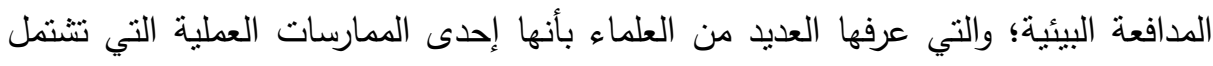

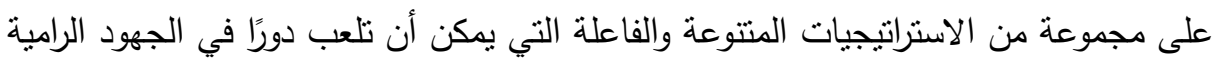

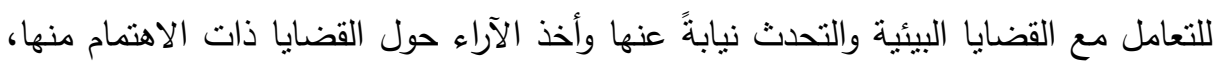
ومن أجل تحقيق رؤية أكثر وضوحًا عنها لتتمكن من تتخيصها وتحليلها واكتثاف أسبابها

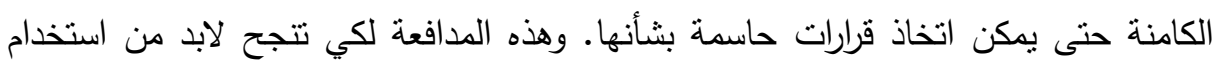

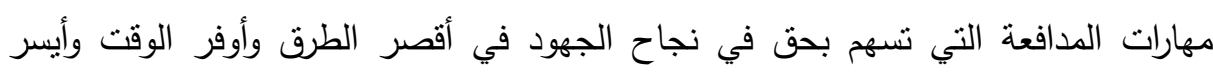
السبل (2010: Edward A. Johnson, Michael J. Mappin). ولما كان أفراد المجتمع يعتمدون على الاعلام كمصدر أساسي للحصول عن معلومات

عن البيئة (Seller, L. \& Jones, D: 1976)

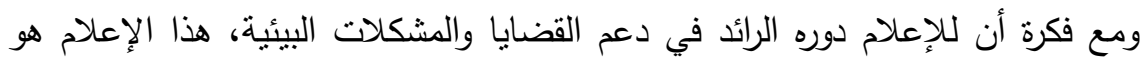

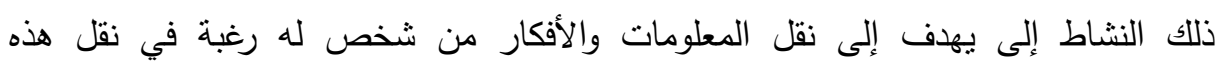


المعلومات (الإعلامي) إلى شخص آخر (المستمع) بهدف إحاطته علمًا بها. فالمعلومات سواء

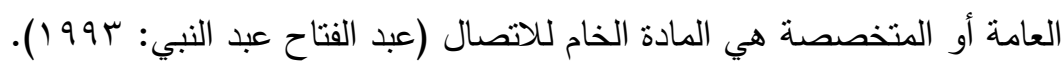

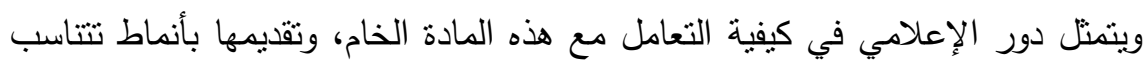

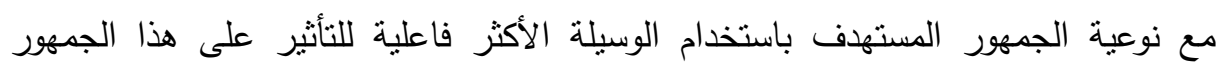
(سمير حسين: (99) (199).

ومع تعدد النظريات التي تؤكد أهمية الدور الذي تقوم به وسائل الإعلام في التأثنر على الجماهير وإقناعهم، فإن نجاح وسائل الإعلام في القيام بمهنتها تجاه التوعية بالقضايا البيئية في العصر الحديث، ينوقف على قيامها بدورها في تتمية الوعي البيئي بكفاءة وفاعلية، فإن

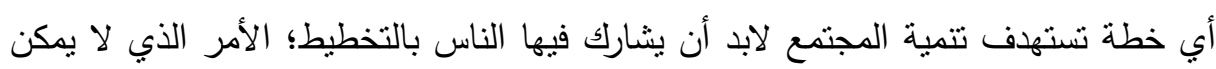

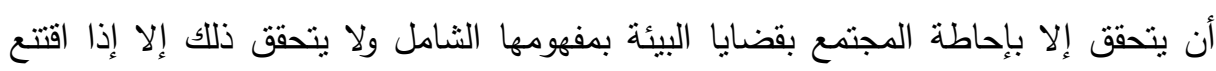
الناس، والطريق إلى هذا الاقتتاع يمر عبر وسائل الإعلام (جيهان رشتي: (991 (19). وتتشير دراسة (Chase, Steve: 2006) إلى أهمية وضع استراتيجية لحل المشكلات

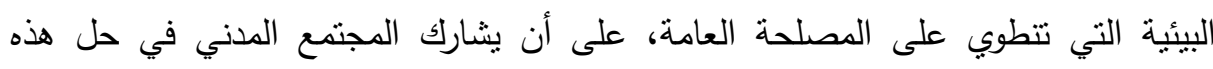
المشكلات والقضايا البيئية، واستهدفت دراسته تطوير برامج في المدافعة البيئية لتدريب

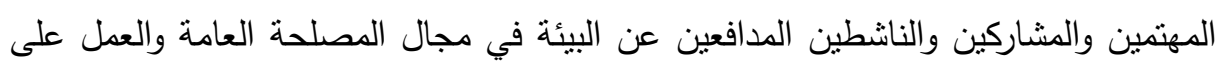
حلها مع قاعدة شعبية. كما أنه من أساسيات المدافعة، أنها تتنمل على المهارات الموجهة للتصدي للتغيير،

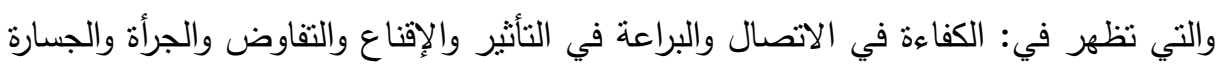

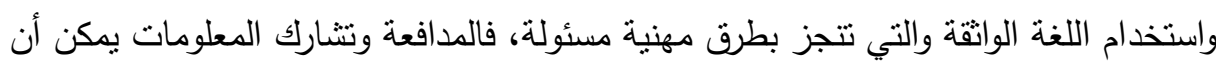

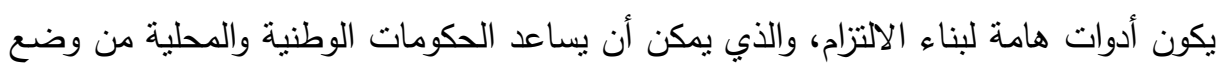

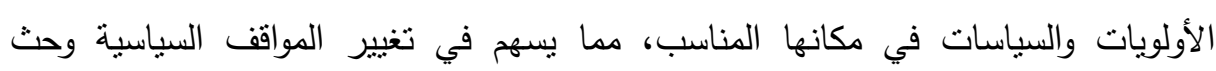

الأنشطة حول موضوع المدافعة. (World Bank:2005) ولما كانت الإذاعة (الراديو) كوسيلة إعلامية لها صفة الثيوع والانتشار والتوجيه، وتحتل المركز الأول بين غيرها من وسائل الاتصال الجماهيري، فقد أصبح الراديو جزءًا هامًا لألاءئا لازمًا

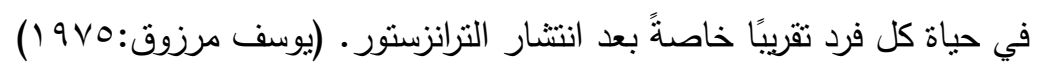


إن الإذاعة قادرة على تغيير وتكوين اتجاه جديد للمستمع على نحو يتماشى ورسالة المصدر، ويبدو ذلك واضحًا في تعدد برامجها الثقافية والدينية والأغاني والموسيقى وغيرها، وتوظيف تلك الأثكال لخدمة البيئة، مما يؤدي إلى تعاظم دور الإذاعة السمعية في التوجه الذي يرمي إلى تعريف العالم بالمشاكل البيئية. (مصطفى محمد عيسى:A9199 ( ) )

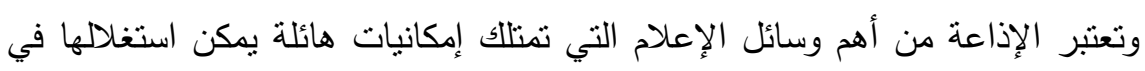

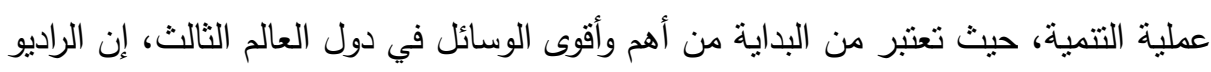

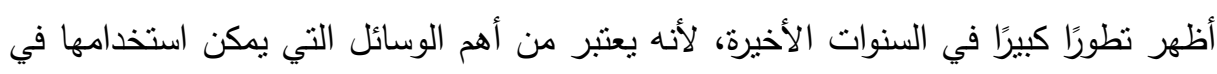
عملية التتمية حيث يستطيع أن يفعل الكثير (نادية سالم: ب9 و 1 ).

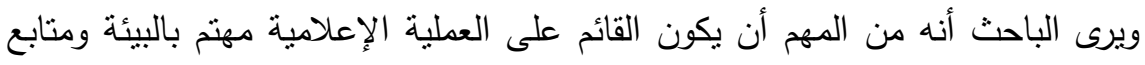

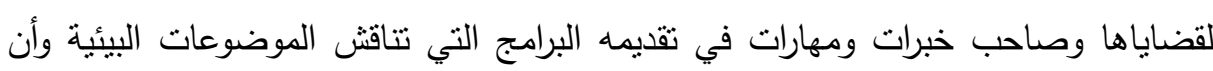
يكون صاحب دور في المدافعة البيئية بإتقانه لمهاراتها. إن الإعلام المصري له دور رائد ومتميز في عمليات التتمية بكافة صورها وأنثكالها، وكم فئه شاركت الإذاعة المصرية في حملات تدعم شتى المجالات: الصحية والتعليمية والاقتصادية والاجتماعية والسياسية والبيئية، وقد أثمرت تلك الحملات بدرجات مختلفة مما يؤكد فاعلية الإعلام متمثلاً في الراديو في تتمية الوعي لدى المواطنين، ولئهة وفذا ما أثنتته الدراسات السابقة المحلية والعالمية. من كل ما سبق برى الباحث أنه لابد من تزويد الإعلاميين بمهارات المدافعة البيئية، بل

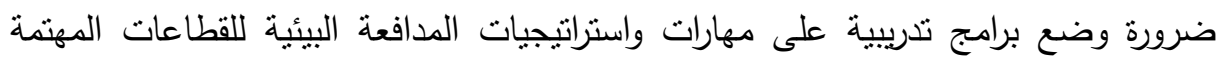
بالبيئة كل تبع تخصصه وإمكاناته وقدراته (الصحفيين، المعلمين، الدعاة، قادة الرأي، الطلاب) برابل

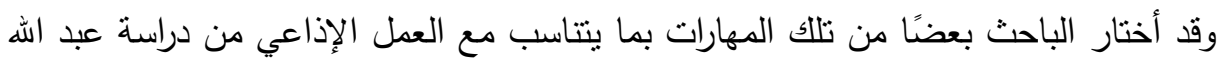

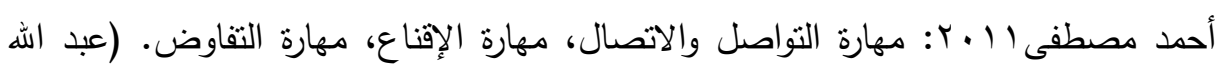

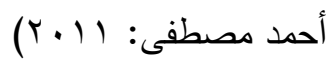




\section{إلجراعايت المهيث}

• تحديد قائمة بمهارات المدافعة البيئية وفروعها.

• إعداد قائمة بالقضايا البيئية المحلية.

• تصميم البرنامج المقترح لنتمية مهارات المدافعة البيئية.

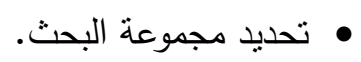

• تحديد مجالات البرنامج المكانية والبشرية والزمنية.

$$
\text { • • تحديد أهداف ومحتوى واستراتيجيات البرنامج. }
$$

• تصميم بطاقة ملاحظة لقياس مهارات المدافعة البيئية.

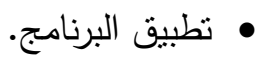

• استخدام الأساليب الإحصائية لحساب النتائج ومعالجتها.

الإجابة على السؤال الأول: ما مهارات المدافعة التي يجب توافرها في القائمين على

إعداد قائمة بمهارات المدافعة البيئية: قام الباحثون بالاطلاع على العديد من الدراسات

$$
\text { السابقة في مهارات المدافعة مثل دراسات: }
$$

(Chase, Steve 2006; Bunyan Bryant 2008; Dick de Jong 2009; Edward

‘A. Johnson 2010; Lisa M. Pohlman 2013; Andrew Patrick 2013)

$$
\text { عبد اله أحمد مصطفى r. r. }
$$

وقد وجد أن الباحثين قد أجمعوا على أن مهارات المدافعة تعتمد على الدفاع والتفاعل

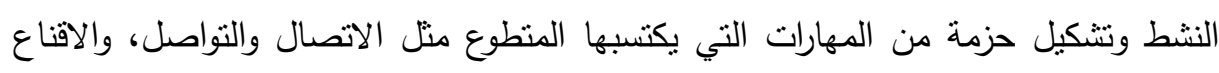

$$
\text { والتفاوض والنتاور وحل المشكلات وحشد المواطنين وغيرها. }
$$

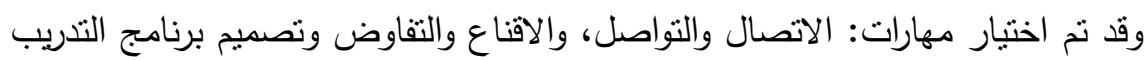

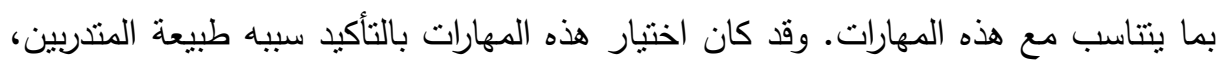
وهم القائمين على البرامج بالإذاعة المصرية، الذين يقدمون للمستمع المصري المعلومة البيئية،

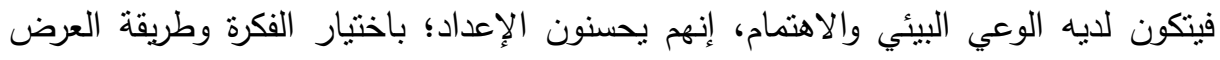
وتسلسل النقاط وتتابع الأسئلة واختيار الضيوف بل واختيار الموسيقى الملائمة. إنهم يقدمون 
وجبة بيئية متكاملة يتواصل بها مقدم البرامج مع المستمع؛ يحاوره ويقنعه بالفكرة ليكسب

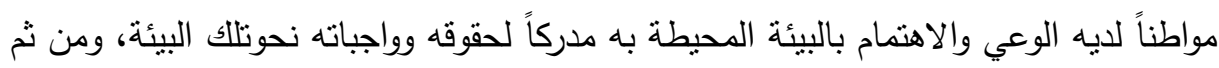
يشارك الاخرين في الدفاع عن البيئة. الإجابة عن السؤال الثاني: ما القضايا البيئية التي يجب تضمينها في البرنامج التدريبي؟ إعداد قائمة القضايا البيئية: لما كان البرنامج سيعمل على تعريف وتأسيس مدافعين

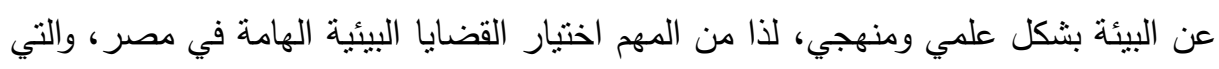

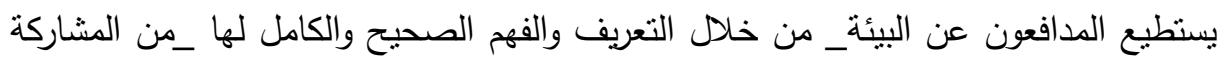
الجادة والقوية في عملية المدافعة عن القضايا البيئية، وفهم الخطوات والاستراتيجيات في

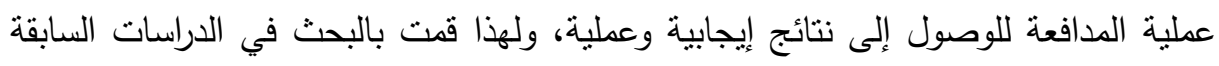

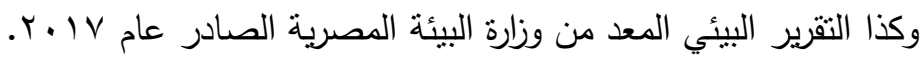
في ضوء ما سبق تم اختيار بعض مواضيع القضايا البيئية المتعلقة بالبيئة والتي تسهر في الإثراء المعرفي للمتدربين مقدمي البرامج بالإذاعة المصرية ومن خلالها نعمل على نتمية

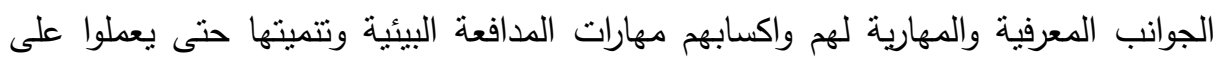
تقديم برامجهم الإذاعية على نحويخدم البيئة والمجتمع.

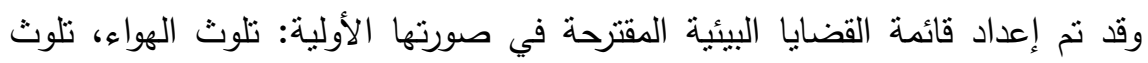
الماء، القمامة، الضوضاء، التتوع المناخي. وكان قد تم سؤال عدد من الزملاء من مقدمي البرامج البيئية من خلال اجراء استنيان

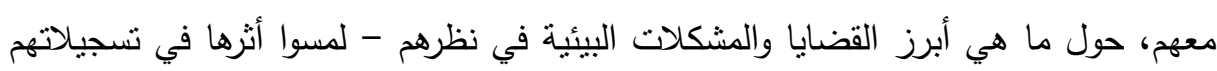
- على المجتمع المصري. كما تم عرض القائمة على عدد من السادة المحكمين من الخبراء والمتخصصين في مجال التربية البيئية والاعلام البيئي لإبداء الرأي فيها ولمعرفة مدى مناسبة تلكائ القضايا والفئة

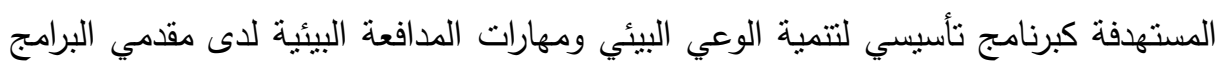
بالإذاعة وبعدها تم اختبار مجموعة من القضايا. 
القضايا البيئية في صورتها النهائية وهي: (تلوث الهواء - تلوث الماء - القمامة). جدول (1): القضايا البيئية في صورتها النهائية

\begin{tabular}{|c|c|c|}
\hline المؤشرات الدالة عليها & القضية & الرئيسية \\
\hline 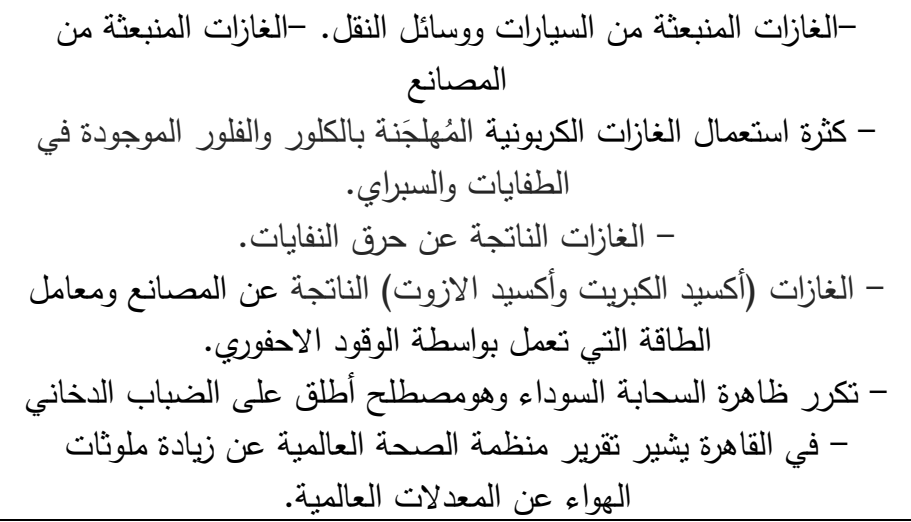 & تلواء & التلوث \\
\hline 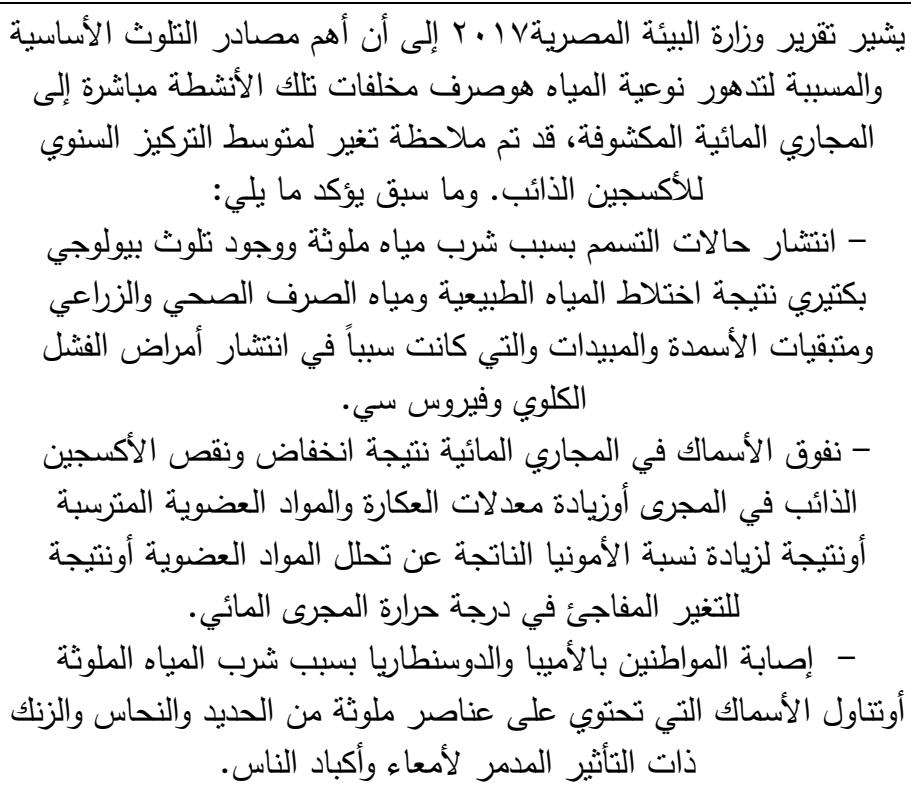 & تلوث & \\
\hline
\end{tabular}




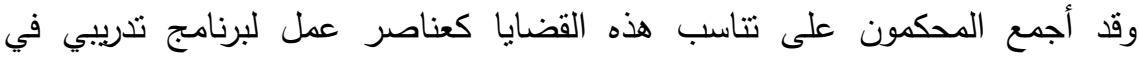

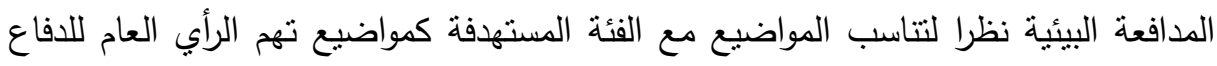

• تم اجراء هذا البحث بمبنى الإذاعة والتلبفزيون بماسبيرو، القاهرة.

• أهنم المسئولون بإجراء منل هذه البحوث لما فيه من تتمية وتدريب لمقدمي البرامج.

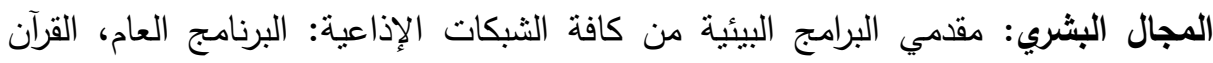

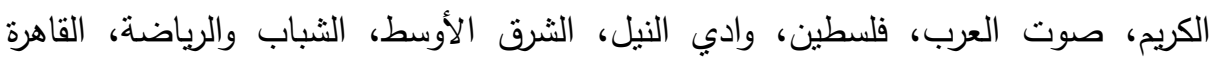
الكبرى، الثقافية، الموجهات.

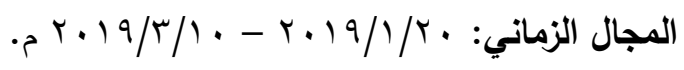

الإجابة على السؤال الثالث: ما التصور المقترح للبرنامج التدريبي المعد لتدريب القائمين

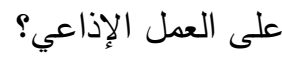


إعداد البرنامج المقترح: نطلب ذللك الاطلاع على الدراسات السابقة والبحوث في مجال تصميم البرامج التدريبية وذلك بهدف التعرف على خطوات بناء البرنامج وكيفية صياغته واستراتيجيات التدريب المختلفة لاختيار الأنسب منها للوصول للهدف التدريبي. صياغة محتوى البرنامج وتنظيمه: تم صياغة محتوى البرنامج في ضوء الأهداف العامة

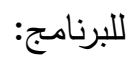

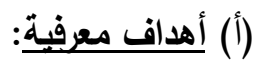
ا • بعرف المدافعة البيئية. r. بفهم مهارات المدافعة البيئية. r. تضح له أداءات كل مهارة. ع. يعي المشكلات البيئية المحلية. ه. يجمع بيانات عن المشكلات البيئية وأسبابها. 7 . يحلل المشكلات البيئية للتعرف على أسبابها الحقيقية.

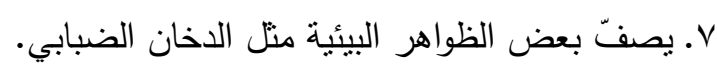
^. يصفّ الوضع الراهن للمشكلات البيئية التي سيشارك بها. 9. يعرف العمل الذي يقوم به الددافع وينجزه بنجاح. • ا ـ يُقوَم المدافعون جهود العمل الذي قاموا به بشكل شفهي أوكتابي. ب - أهداف وحدانبة: ا ـ يعي مقدم البرامج أهمية العمل الجماعي لمواجهة المشكلات البيئية. r r بستعد لمواجهة التحديات التي تواجه البيئة. r. يعي الأخطار التي تواجه البيئة المحلية. ع. يكوّن المدافع شعوراً بالمسئولية الفردية التي تعود بالفائدة على البئة البئة ككل.

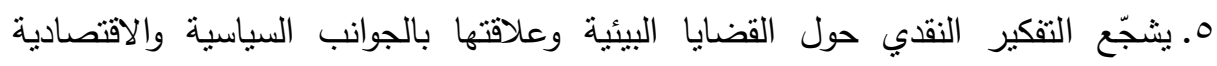
والاجتماعية والثقافية في محاولة لتتمية قدرات حل المشكلات. 7. يثير امتعاض المدافع ما يحدث للبيئة من أضرار. 
V. يأخذ مقدم البرامج المبادرة للدافعة البيئية في المجتمع والعمل من أجل التغيير الإيجابي

$$
\text { للبيئة. }
$$

^. يعبر عن القيم داخل المجتمع من خلال التركيز على القضايا البيئية المحلية. 9 ـ ينمي العاطفة نحوالقضايا البيئية.

• ال ـ يدعم المبادرات الهامة لضمان المدافعة البيئية.

ا ا ـ يعزز النقاش حول المشكلات والقضايا البيئية.

r ا ـ يوجه مقدم البرامج المساءلة للمؤسسات المسئولة عن شئون البيئة حتى تكون أكثر جدوى

للمشكلات البيئية.

با ـ يتخذ المقدم مواقف تتطلب قدراً كبيراً من المسئولية.

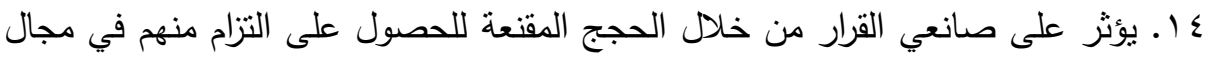

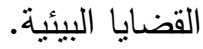

1 ـ يسعى مقدم البرامج على التوسط لعمل شراكات عامة لاعم المواقف التي تعزز سلامة

ج - أهداف مهارية:

ا ـ يكتسب مقدم البرامج مهارات الددافعة البيئية.

r. بتدرب المقدم على ممارسة مهارات المدافعة المكتسبة في بيئة عمل فعلية من خلال بله أنشطة البرنامج.

r. يقوم المدافع بعرض المهارات التي اكتسبها أمام زملائه عملياً. ع. يستخدم مقدم البرامج استراتيجيات: حل المشكلات، لعب الأدوار، والتعلم التعاوني للتخطيط لمواجهة المشكلات البيئية.

ه. يشترك مقدم البرامج في جهود المدافعة من خلال المشروعات البيئية. 7. يقوم المدافع بجمع المعلومات من مصادر منتوعة عن المشكلات البيئية. V. يعد برامج إذاعية تصف كيفية التلوث وطرق مواجهته. ^. يتخذ المقدم المدافع قرارات بيئية أخلاقية.

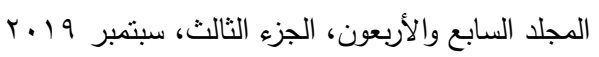


9. يقوم المقدم باشراك الجمهور لمواجهة القضايا البيئية وحثدهم للعمل على حماية المجتمع

$$
\text { المحلي من آنارها الضارة. }
$$

• 1 . يحث مقدم البرامج كل من له شأن بشئون البيئة بأن يستخدم الإمكانات المختلفة للمدافعة

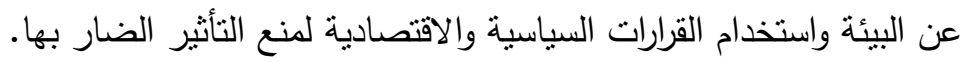
محتوى البرنامج المقترح: عبارة عن مجموعة من أهم القضايا والمشكلات البيئية ومجموعة لئنة

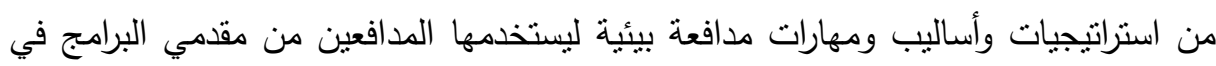
أنشطة البرنامج حنى يحقق أهدافه. عناصر محتوى البرنامج المقترح: ( ) (بائمة القضايا البيئية.

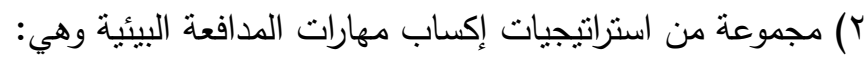
(أ) استراتيجية لإكساب مقدمي البرامج مهارات المدافعة البيئية.

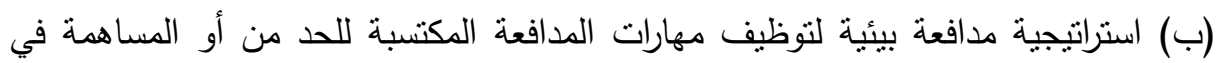

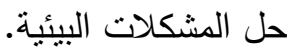
(ج) استراتيجية مدافعة بيئية لمواجهة المشكلات البيئية. يمكن عرض هذه الاستراتيجيات على النحو التالي: (أ) استراتيجية اكساب المقدمين مهارات المدافعة البيئية: وهي تتنتمل على المراحل التالية: أولاً: مرحلة تقديم المهارة. ثانياً: مرحلة تعلم المهارة. ثالثاً: مرحلة اكتساب المهارة. رابعاً: مرحلة انقان المهارة. (ب) استراتيجيات توظيف المهارات المكتسبة: وتتنتمل على المراحل التالية: أولاً: التحضير للإجراء العملي للمهارة. ثانياً: أثناء تقديم المهارة، وتتمنل في الإجراءات التي تزيد من فاعلية عرض المهارة. ثالثاً: ما بعد التقويم. ويتم كالاتي: مراجعة القواعد. والثقويم الذاتي. (ج) تحديد استراتيجية مدافعة بيئية لمواجهة المشكلات البيئية: تتضمن مجموعة من الأساليب والوسائل منها: ا ـ تحديد الجمهور المستهدف. 


$$
\begin{aligned}
& \text { r r r وصف المشكلة موضوع المدافعة وتحديدها. } \\
& \text { r. جمع المعلومات الأساسية ذات الصلة بالمشكلة. } \\
& \text { ء. تحديد أهداف محددة قابلة للقياس وتكون متصفة بالثمول والاتساع. } \\
& \text { ه. تحديد الإطار الزمني للتنفيذ. } \\
& \text { 7. تحديد الثراكات أومع من يمكن أن نعمل. } \\
& \text { V. تحديد الرسالة ووسيلة التعبير عنها (حديث مباشر ، تحقيق، ندوة، دراما). } \\
& \text { ^. التقييم وكتابة التقارير • } \\
& \text { 9. رسم خطة العمل. } \\
& \text { • } 1 \text { ـ تحديد المخاطر والقيود المتوقع حدوثها. }
\end{aligned}
$$

r) الأساليب والأدوات المستخدمة: الحديث المباشر ؛ التحقيق الإذاعي؛ الحوار المباشر؛ ندوة؛

$$
\text { الفوازير ؛ المسابقات؛ سلوجان؛ الدراما. }
$$

ع) الثراكات والتحالفات: وهي تسهم في تحقيق أهداف البرنامج، من خلال دعم السياسات الني تعزز سلاهة البيئة، ويمكن أن تقوم الثراكات مع: شراكة مع وزارة البيئة المصرية؛ شراكة مع وزارة التربية والتعليم؛ شراكة مع الجمعيات المهتمة بالبيئة؛ شراكة مع المسئولين

$$
\text { التتفيذين بالحي. }
$$

0) مهارات المدافعة البيئية المستخدمة في أنشطة البرنامج: مهارة الاقناع؛ مهارة الاتصال؛

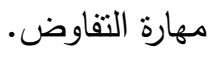

إعداد أداة البحث (بطاقة ملاحظة مهارات المدافعة البيئية): (أ) بناء بطاقة ملاحظة وفق الخطوات التالية:

- - تحديد هدف البطاقة ويتمثل في التعرف على مهارات المدافعة البيئية التي اكتسبها مقدمي

$$
\text { البرامج من خلال البرنامج. }
$$

$$
\text { - تحديد أداءات كل مهارة من مهارات المدافعة البيئية. }
$$

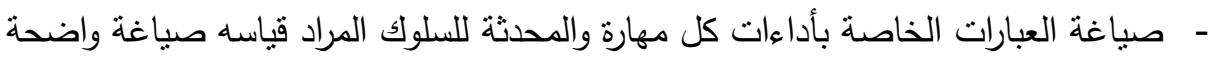

$$
\text { تبدأ بفعل سلوكي في زمن الحاضر . }
$$


- استخدام سلم تقدير بعتمد على ألفاظ متدرجة تعكس مستويات متدرجة من الجودة والاتقان

لكل أداء من أداءات المهارة.

- تحويل التقديرات اللفظية (الاستجابات الملحوظة) إلى تقديرات كمية حتى يمكن جمع

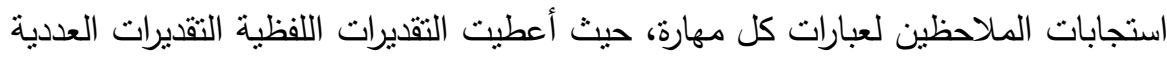

التالية:

• قام بالممارسة بدرجة عالية، تعطى ثلاث درجات.

• • قام بالممارسة بدرجة متوسطة، تعطى درجتان.

• • قام بالممارسة بدرجة منخفضة، تعطى درجة واحدة.

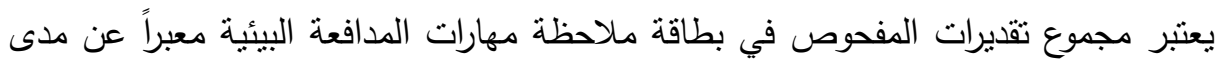

اكتسابه لمهارات المدافعة البيئية.

إعداد تعليمات البطاقة لتكون على النحو التالي:

• أن تكون التعليمات الموجهة للمفحوص على قدئل قدر كبير من الوضوح والدقة.

• ت تعريف المفحوص بطبيعة المهمة المطلوب أن يقوم بها.

• أن يركز الفاحص على العملية والناتج معاً.

إعداد وتتظيم أسلوب وطريقة الملاحظة المستخدمة في تقويم الأداء لتكون على النحو التالي:

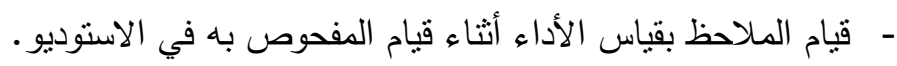

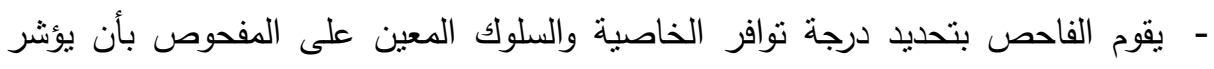
على قيمة التقدير المناسب.

(ب) حساب صدق بطاقة الملاحظة:

صدق المحكمين: بعرضها في صورتها المبدئية على مجموعة من المحكمين لإبداء الرأي في

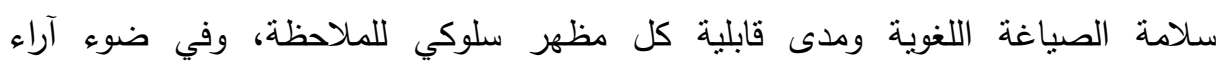
وملاحظات المحكمين نم تعديل بعض أداءات المهارات في البطاقة إما بالحذف أوتعديل الصياغة.

التأكد من ثبات بطاقة الملاحظة من خلال تطبيقها على (0) من مقدمي البرامج من خارج عينة الدراسة، حيث تمت ملاحظتهم من قبل الباحث. 
وقد نم حساب معامل الصدق باستخدام الاتساق الداخلي لحساب معامل الارتباط لبطاقة

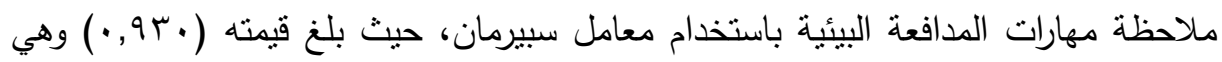
قيمة دالة عند مستوى (0.01) مما يدل على وجود اتساق داخلي مرتفع للبطاقة، ومما يدل أنها على درجة عالية من الصدق.

كما تم حساب معامل الثبات لبطاقة الملاحظة بطريقة ألفا كرونباخ حيث بلغ قيمته منه

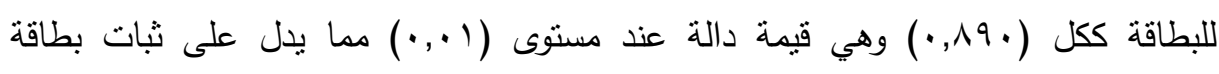
الملاحظة واعتبرت هذه القيمة كافية لأغراض الدراسة وبذلك أصبحت بطاقة الملاحظة في صورتها النهائية. شملت الصورة النهائية لبطاقة الملاحظة ثلاث مهارات أساسية وهي مهارة الاقناع

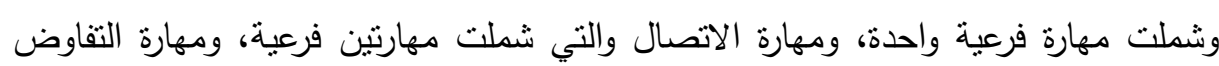
وشملت مهارة فرعية واحدة.

تم تطبيق البرنامج المقترح، وتجريب بطاقة الملاحظة لمهارات المدافعة البيئية بمبنى

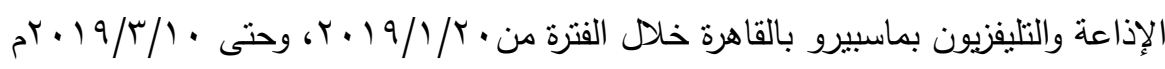

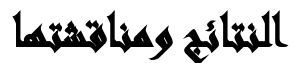

$$
\text { يمكن ايجاز أهم النتائج التي توصل إليها البحث على النحو التالي: }
$$

تفسير نتائج الفرض الأول: ينص الفرض الأول على أنه: توجد فروق ذات دلالة إحصائية بين منوسطي درجات المبحوثين قبل تعرضهم لبرنامج قائم على تتمية مهارات المدافعة البيئية وبعد التعرض له على بعد مهارة الاتصال لصالح القياس البعدي.

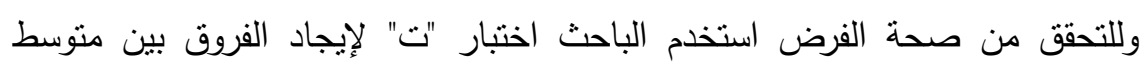
درجات مبحوثين المجموعة التجريبية بعد تعرضهم لبرنامج قائم على تتمية مهارات المدافعة

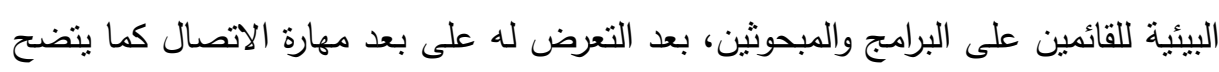

في جدول (r) (بئه ) 
جدول (Y): الفروق بين متوسط درجات مبحوثين المجموعة التجريبية قبل تعرضهم لبرنامج قائم على تتمية مهارات المدافعة البيئية والمبحوثين بعد التعرض له له على مهلى مهارة

$$
\text { الاتصال ن = . ع }
$$

\begin{tabular}{|c|c|c|c|c|c|c|c|}
\hline \multirow[t]{2}{*}{ اتجاه الدلالة } & \multirow{2}{*}{ مستوى الدلالة } & \multirow[t]{2}{*}{$ت$} & \multicolumn{2}{|c|}{ التطبيق البعدي } & \multicolumn{2}{|c|}{ التطبيق القبلي } & \multirow{3}{*}{ الاتصال } \\
\hline & & & r & $r_{p}$ & $1 \varepsilon$ & م & \\
\hline الصنالح & دالة عند & $r_{\cdot}, 9 \wedge T$ & r,V৭ & rV, q. & $r, 1 \wedge r$ & IV, ro & \\
\hline
\end{tabular}

ينضح من جدول (Y) وجود فروق دالة احصائيًا عند مسنوى 1 (, • بين منوسط درجات المبحوثين بعد تعرضهم لبرنامج قائم على تتمية مهارات المدافعة البيئة والتطبيق القبلي للبرنامج وذللك على مهارة الاتصال لبطاقة الملاحظة لصالح التطبيق البعدي للبرنامج، حيث

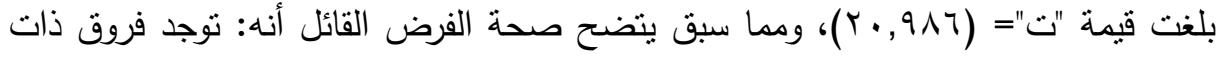
دلالة إحصائية بين متوسطي درجات المبحوثين قبل تعرضهم لبرنامج قائم على تتمية مهارات

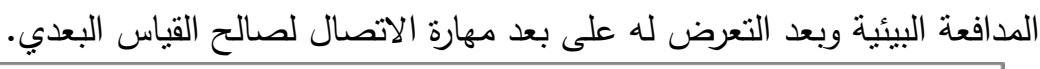

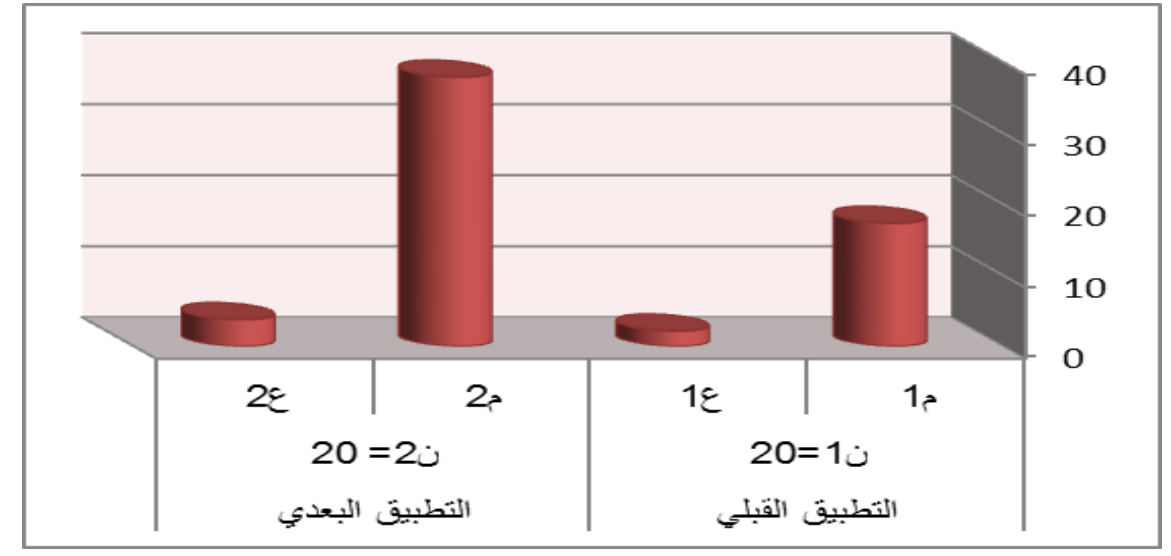

شكل (1): الفروق بين منوسط درجات المبحوثين بعد تعرضهم لبرنامج تتمية مهارات المدافعة البيئية ودرجاتهم قبل نطبيق البرنامج على بعد مهارة الاتصال 
تفسير نتائج الفرض الثاني: ينص الفرض الثاني على أنه: نوجد فروق ذات دلالة إحصائية بين متوسطي درجات المبحوثين قبل تعرضهم لبرنامج قائم على تتمية مهارات

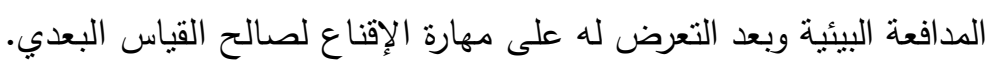

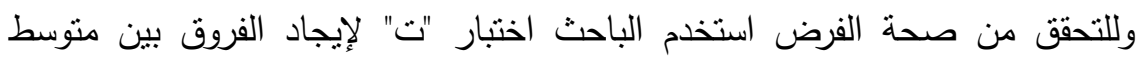
درجات مبحوثين المجموعة التجريبية بعد تعرضهم لبرنامج قائم على تتمية مهارات المدافعة

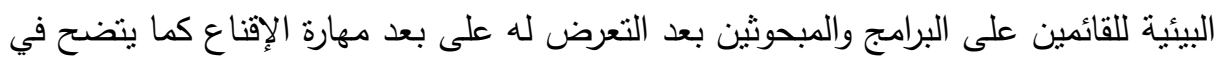
جدول (r). جدول (ץ): الفروق بين متوسط درجات مبحوثين المجموعة التجريبية قبل تعرضهم لبرنامج

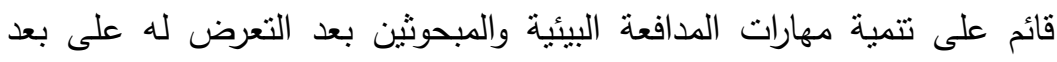

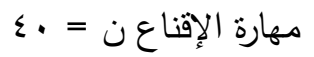

\begin{tabular}{|c|c|c|c|c|c|c|c|}
\hline \multirow{2}{*}{ الدالة } & \multirow{2}{*}{ مستوى الالاية } & \multirow[t]{2}{*}{$ت$} & \multicolumn{2}{|c|}{ 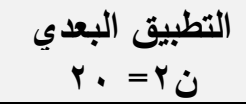 } & \multicolumn{2}{|c|}{ التطبيق القبلي } & \multirow{5}{*}{ مهارة الإقناع } \\
\hline & & & $r \varepsilon$ & $r_{p}$ & $1 \varepsilon$ & م & \\
\hline لصالح & دالة عند & & & & & & \\
\hline التطبيق & مستوى & $r r, .9 q$ & $r, \wedge \wedge \wedge$ & $r \varepsilon, 70$ & $r, r V V$ & 10,70 & \\
\hline البعدي & $\cdot, \cdot 1$ & & & & & & \\
\hline
\end{tabular}

يتضح من جدول (r) وجود فروق دالة احصائيًا عند مستوى ا.,.• بين منوسط درجات المبحوثين بعد تعرضهم لبرنامج قائم على تتمية مهارات المدافعة البيئة والتطبيق

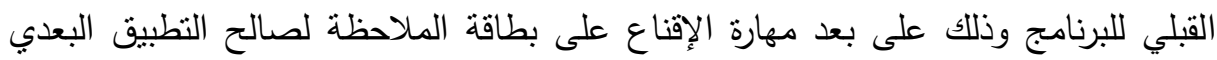

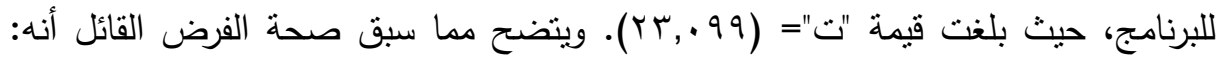
توجد فروق ذات دلالة إحصائية بين متوسطي درجات المبحوثين قبل تعرضهم لبرنامج

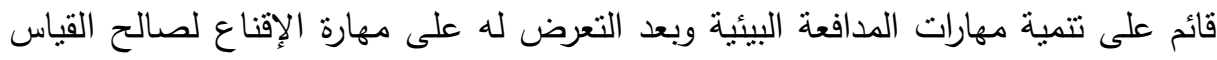

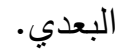




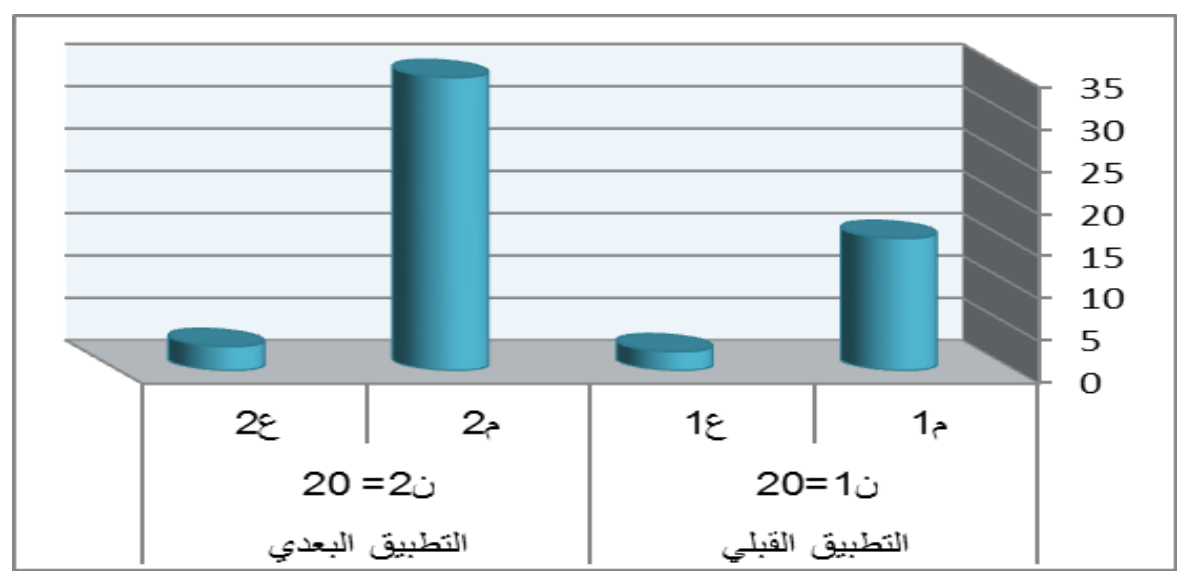

شكل (ץ): يوضح الفروق بين متوسط درجات المبحوثين بعد تعرضهم لبرنامج تتمية مهارات

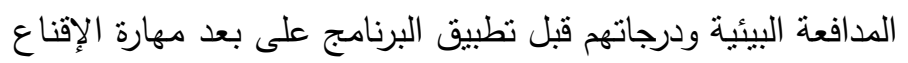

تفسير نتائج الفرض الثالث: ينص الفرض الثالث على أنه: نوجد فروق ذات دلالة

إحصائية بين منتسطي درجات المبحوثين قبل تعرضهم لبرنامج قائم على تتمية مهارات

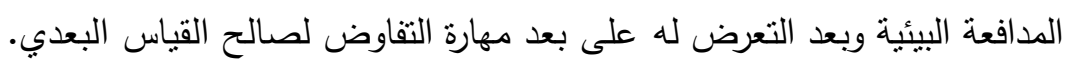

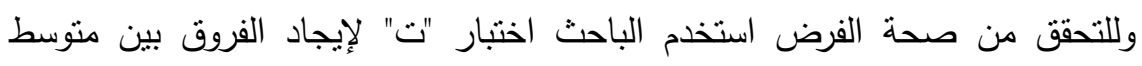
درجات مبحوثين المجموعة التجريبية بعد تعرضهم لبرنامج قائم على تتمية مهارات المدافعة

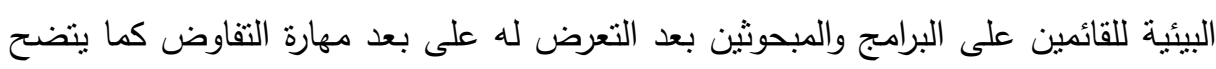

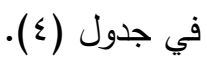

جلول (؛): الفروق بين منوسط درجات مبحوثين المجموعة التجريبية بعد تعرضهم لبرنامج

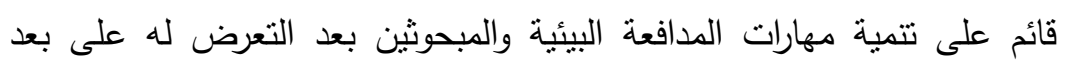

مهارة التفاوض ن = . ع

\begin{tabular}{|c|c|c|c|c|c|c|c|}
\hline \multirow{2}{*}{ الدالة الداه } & \multirow{2}{*}{ مستوى } & \multirow[t]{2}{*}{$ت$} & \multicolumn{2}{|c|}{ 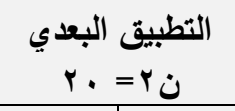 } & \multicolumn{2}{|c|}{ التطبيق القبلي } & \multirow{4}{*}{ مهارة التفاوض } \\
\hline & & & $r \varepsilon$ & $r^{p}$ & $\varepsilon$ & م & \\
\hline لصالح & دالة عند & & & & & & \\
\hline التطبيق & مستوى & $Y 0,7) \leqslant$ & $r, r q \leq$ & ס, חr & $r, r \leqslant \varepsilon$ & $1 \varepsilon, \vee 0$ & \\
\hline
\end{tabular}


يتضح من جدول (ع) وجود فروق دالة احصائيًا عند مستوى | .,. • بين متوسط درجات المبحوثين بعد تعرضهم لبرنامج قائم على تتمية مهارات الددافعة البيئة والتطبيق القبلي لبني للبرنامج وذللك على بعد مهارة التفاوض على بطاقة الملاحظة لصالح النطبيق البعدي

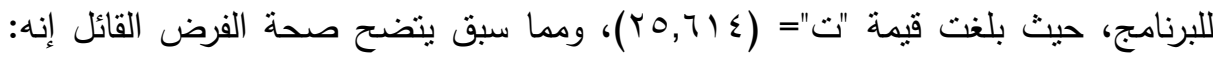
توجد فروق ذات دلالة إحصائية بين متوسطي درجات المبحوثين قبل تعرضهم لبرنامج قائم على تتمية مهارات المدافعة البيئية وبعد التعرض له على بعد مهارة التفاوض لصالح

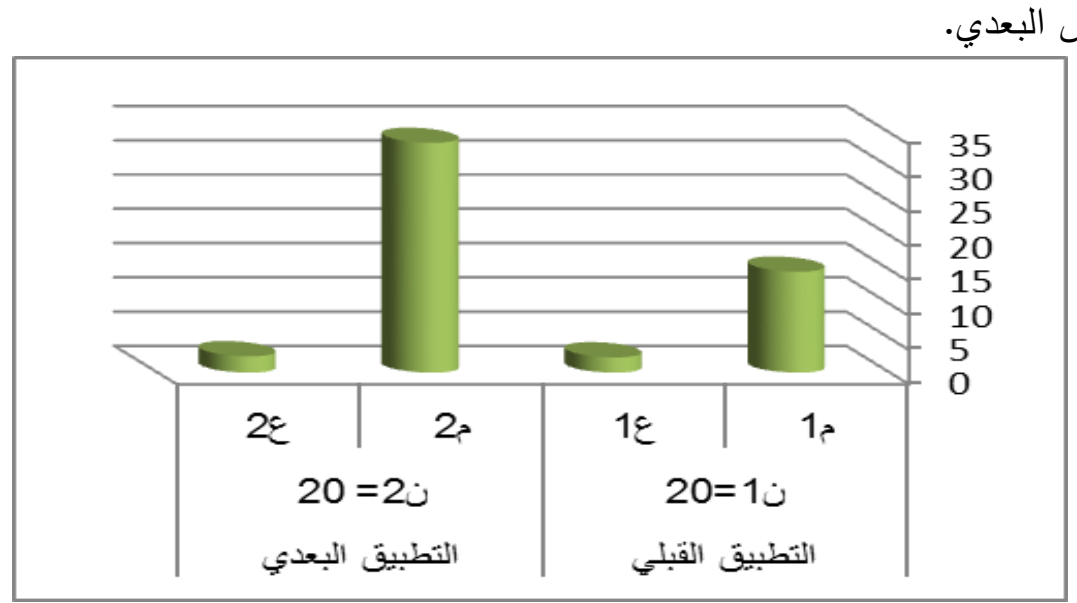

شكل (r): يوضح الفروق بين منوسط درجات المبحوثين بعد تعرضهم لبرنامج تتمية مهارات

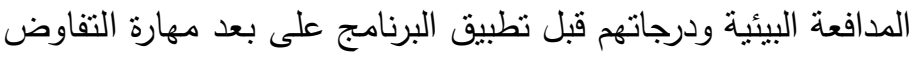
تفسير نتائج الفرض الرابع: ينص الفرض الرابع على أنه: توجد فروق ذات دلالة إحصائية بين متوسطي درجات المبحوثين قبل تعرضهم لبرنامج قائم على تتمية مهارات المدافعة البيئية وبعد التعرض له على إجمالي بطاقة ملاحظة مهارات المدافعة البيئية لصالح

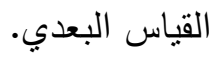
وللتحقق من صحة الفرض استخدم الباحث اختبار " ت" لإيجاد الفروق بين منتسط درجات مبحوثين المجموعة التجريبية بعد تعرضهم لبرنامج قائم على تتمية مهارات المدافعة 
البيئية للقائمين على الاتصال بالبرامج الإذاعية المصرية والمبحوثين بعد التعرض له على

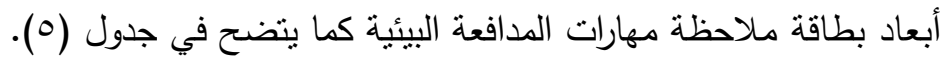
جدول (ه): الفروق بين منوسط درجات مبحوثين المجموعة التجريبية قبل تعرضهم لبرنامج قائم على نتمية مهارات المدافعة البيئية والمبحوثين بعد التعرض له له على أبعاد بطاقة

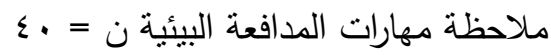

\begin{tabular}{|c|c|c|c|c|c|c|c|}
\hline \multirow[t]{2}{*}{ اتجاه الدلالة } & \multirow{2}{*}{ مستوى الدلالة } & \multirow[t]{2}{*}{$ت$} & \multicolumn{2}{|c|}{ التطبيق البعدي } & \multicolumn{2}{|c|}{ التطبيق القبلي } & \multirow{2}{*}{ بطاقة } \\
\hline & & & $r_{\varepsilon}$ & $r^{5}$ & $1 \varepsilon$ & م & \\
\hline التطبالح & دالة عند & $r v, V 10$ & $0, \wedge \wedge \Gamma$ & $1 \cdot 7,1$. & $r, 7 \leqslant$. & $\varepsilon \vee, V_{0}$ & الكلية \\
\hline
\end{tabular}

يتضح من جدول (0) وجود فروق دالة احصائيًا عند مستوى ا. ب, • بين منوسط درجات

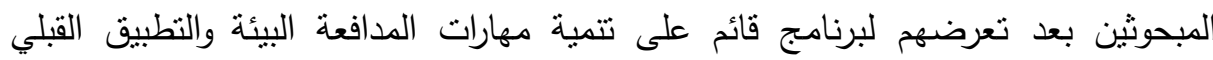

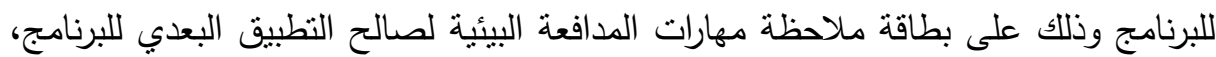

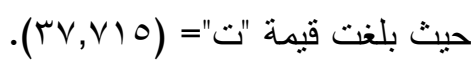

يخلص الباحث مما سبق صحة الفرض القائل أنه: توجد فروق ذات دلالة إحصائية بين متوسطي درجات المبحوثين قبل تعرضهم لبرنامج قائم على تتمية مهارات المدافعة

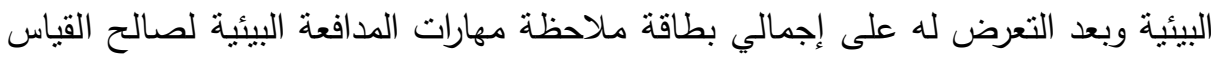

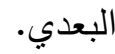




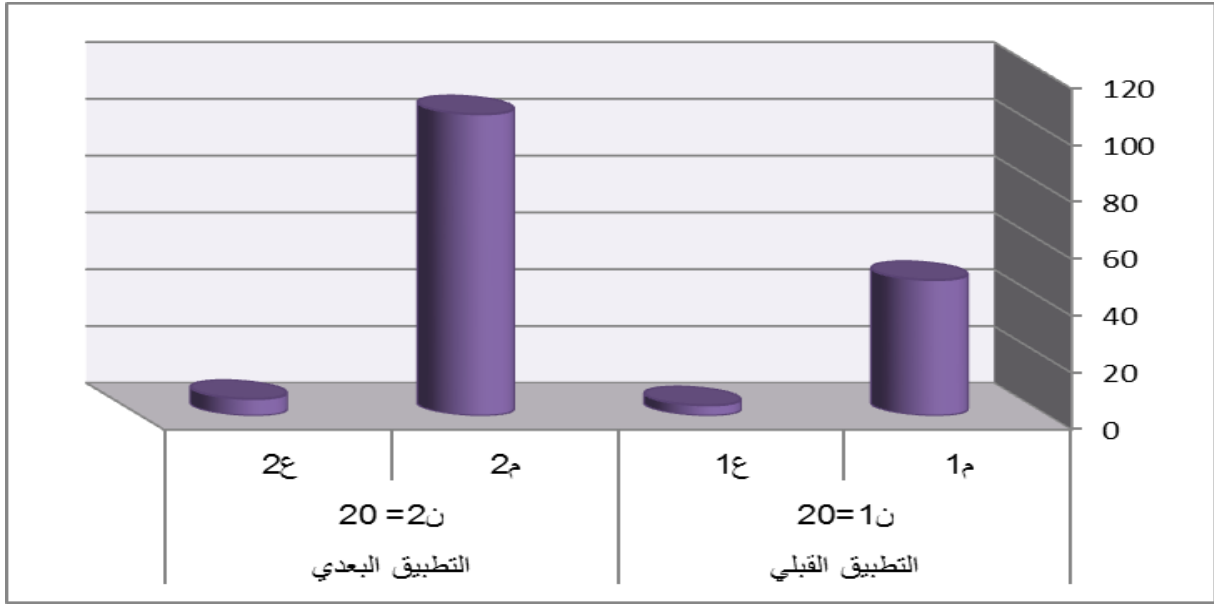

شكل ( ؛): يوضح لفروق بين متوسط درجات المبحوثين بعد تعرضهم لبرنامج تتمية مهارات المدافعة البيئية ودرجاتهم قبل تطبيق البرنامج على إجمالي بطاقة ملاحظة

$$
\text { مهارات المدافعة البيئية }
$$

الفرض الخامس: توجد فروق ذات دلالة احصائية بين منوسط رتب درجات التطبيق قبلياً

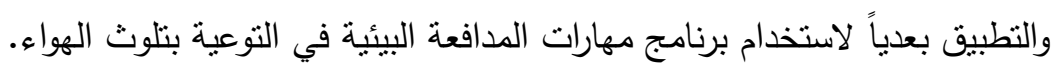

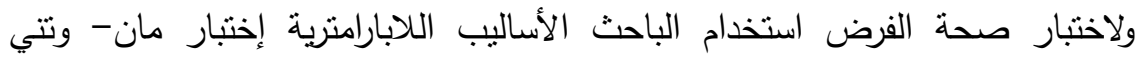

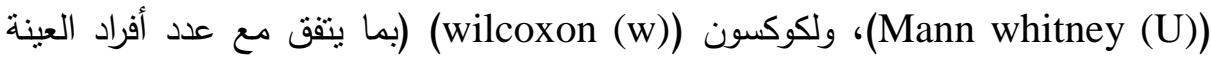
الصغيرة) بين نتائج التطبيق البعدي عن طريق برنامج (WPS 20) وتوصلت إلى الجدول التالي (T). 
جدول (†): قيمة "Z" ودلالة الفروق بين متوسطي رثب التطبيق قبلياً والتطبيق بعديا في

\begin{tabular}{|c|c|c|c|c|c|c|c|c|}
\hline مستوى & الدلالة & قيمة & ولكوكسون & مان - ماني & مجموع الرتب & متوسط الرتب & العدد & المجموعة \\
\hline \multirow{2}{*}{ مسنوى 1 عند } & \multirow[b]{2}{*}{$\cdot, \ldots$} & \multirow[b]{2}{*}{ \&,ror } & \multirow[b]{2}{*}{$1 r \cdot, 0}$. & \multirow[b]{2}{*}{$1 \cdot, 0}$. & ir.,o. & $\Lambda, \vee \cdot$ & \multirow[b]{2}{*}{0} & قبلي \\
\hline & & & & & . & rY,r. & & بعدي \\
\hline
\end{tabular}

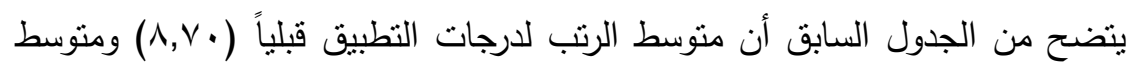

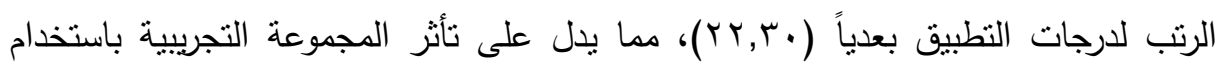

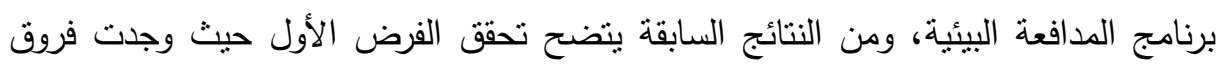

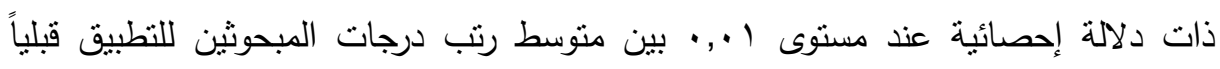
والنطبيق بعدياً، وقد كانت الفروق لصالح التطبيق بعدياً في التوعية بالتلوث الهواء. الفرض السادس: توجد فروف ذات دلالة احصائية بين متوسط رتب درجات التطبيق قبلياً

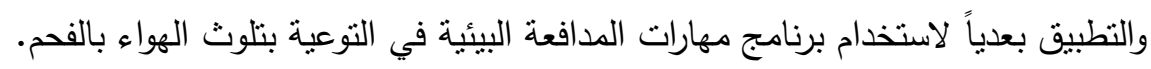

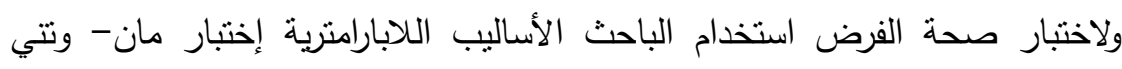

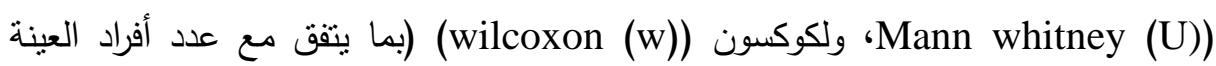
الصغيرة) بين نتائج النطبيق البعدي عن طريق برنامج (SPSS 20) وتوصلت إلى الجدول

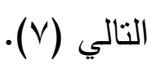
جدول (V): قيمة "Z" ودلالة الفروق بين متوسطي رتب التطبيق قبلياً والنطبيق بعديا في

\begin{tabular}{|c|c|c|c|c|c|c|c|c|}
\hline & & & & \multicolumn{5}{|c|}{ التوعية بتلوث الهواء بالفحم } \\
\hline مستوى الدلالة & الدلالة & قيمة & ولكوكسون & مان - ماني & مجموع & متوسط الرتب & العدد & المجموعة \\
\hline \multirow{2}{*}{ دالة دستوى } & \multirow{2}{*}{$\cdot, \cdots$} & \multirow{2}{*}{$\varepsilon, 77 \wedge$} & \multirow{2}{*}{ r. } & \multirow{2}{*}{$\cdots$} & Kr. & $\wedge$ & \multirow{2}{*}{0} & قبلي \\
\hline & & & & & $r \leqslant 0$ & r & & بعدي \\
\hline
\end{tabular}


يتضح من الجدول السابق أن متوسط الرتب لدرجات التطبيق قبلياً (^) ومتوسط الرتب

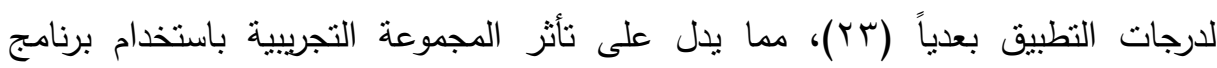

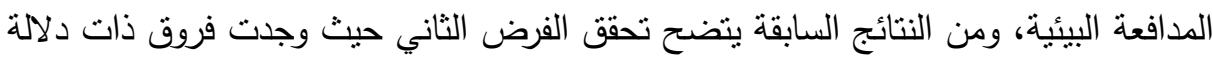

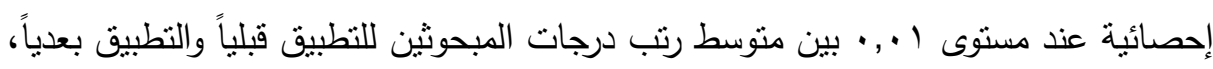
وقد كانت الفروق لصالح التطبيق بعدياً في التوعية بالتلوث الهواء بالفحم. الفرض السابع: توجد فروق ذات دلالة احصائية بين متوسط رتب درجات التطبيق قبلياً

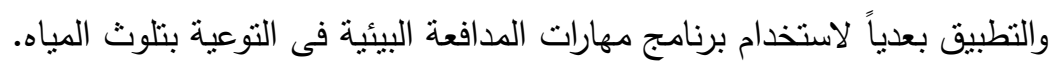

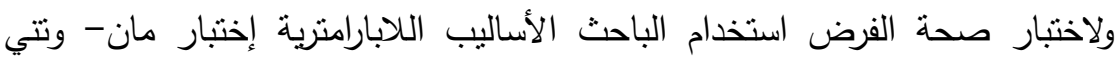

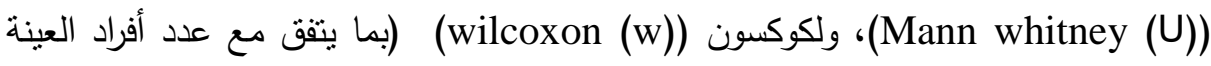

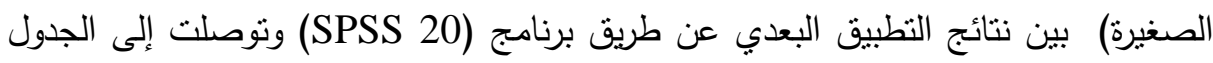

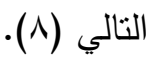
جدول (^): قيمة "Z" ودلالة الفروق بين متوسطي رثب التطبيق قبلياً والتطبيق بعديا فى بـ

\begin{tabular}{|c|c|c|c|c|c|c|c|c|}
\hline & & & & \multicolumn{5}{|c|}{ للتوعية بالتلوث المياه } \\
\hline الدلالة & الدلالة & $\begin{array}{l}\text { قيمة } \\
\text { "Z" }\end{array}$ & ولكوكسون & وتني - مان & الرتبوع & متوسط & العدد & المجموعة \\
\hline \multirow{2}{*}{ مستوى } & \multirow[b]{2}{*}{,,$\ldots$} & \multirow[b]{2}{*}{, $01 \%$} & \multirow[b]{2}{*}{$T r \varepsilon, 0}$. & \multirow[b]{2}{*}{, 0 . } & $T r \varepsilon, O$. & $\Lambda, r$. & \multirow[b]{2}{*}{ o } & قلبي \\
\hline & & & & & $r \leqslant ., 0$. & $r r, v$. & & بعدي \\
\hline
\end{tabular}

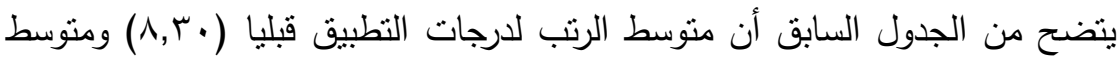

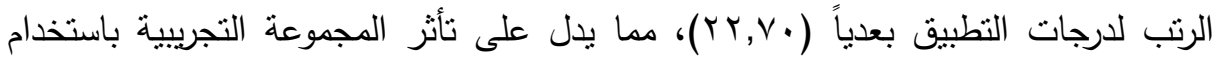

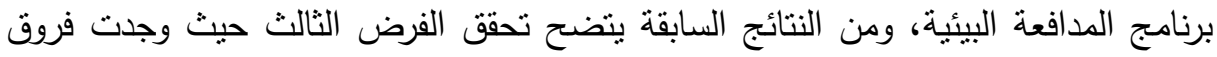

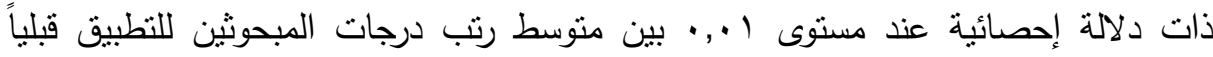

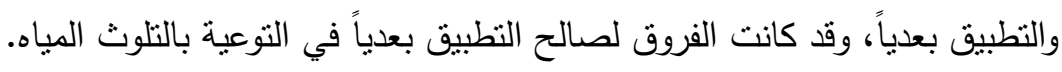


الفرض الثامن: نوجد فروق ذات دلالة احصائية بين متوسط رتب درجات التطبيق قبلياً والنطبيق بعدياً لاستخدام برنامج مهارات المدافعة البيئية في التوعية بخطورة القمامة. ولاختبار صحة الفرض استخدام الباحث الأساليب اللابارامترية إختبار مان- وتتي (

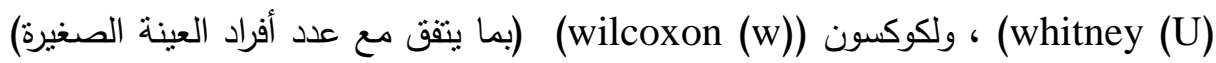

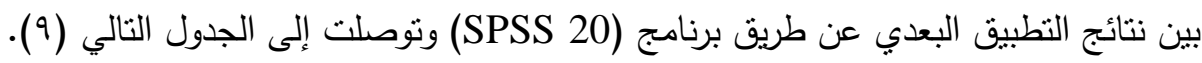
جدول (9): قيمة "Z" ودلالة الفروق بين منوسطي رتب التطبيق قبلياً والتطبيق بعديا في التوعية بخطورة القمامة

\begin{tabular}{|c|c|c|c|c|c|c|c|c|}
\hline مستوى الدلاية & الدلالة & قيمة & ولكوكسون & مان - متني & الرتب & متوسط & العدد & المجموعة \\
\hline \multirow{2}{*}{ دالة عندى } & \multirow{2}{*}{$\cdot, \cdots$} & \multirow{2}{*}{$\varepsilon, V \cdot r$} & \multirow{2}{*}{ Ir. } & \multirow{2}{*}{$\cdots$} & Ir. & $\wedge$ & \multirow{2}{*}{0} & قبلي \\
\hline & & & & & $r \leqslant 0$ & r & & بعدي \\
\hline
\end{tabular}

يتضح من الجدول السابق أن متوسط الرتب لدرجات التطبيق قبلياً (^) ومتوسط الرتب لدرجات التطبيق بعدياً (rr)، مما يدل على تأثر المجموعة التجريبية باستخدام برنامج

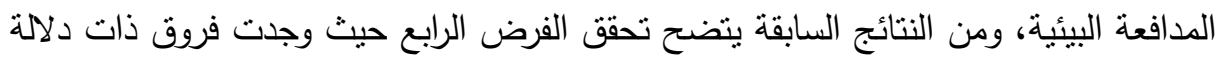
إحصائية عند مستوى ا • ,. · بين منوسط رثب درجات المبحوثين للتطبيق قبلياً والتطبيق بعدياً، وقد كانت الفروق لصالح التطبيق بعدياً في النوعية بخطورة القمامة. خلاصة النتائج: توصل الباحث على أن البرنامج المقترح قد اكسب القائمين على البرامج

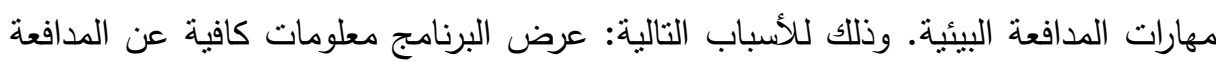
البيئية ومهاراتها (الاتصال- الإقناع - التفاوض) والاستراتيجيات المستخدمة في المدافعة ودئة وخطواتها، وتم استخدام أساليب تدريبية وتدريسية من محاضرات ومناقثات وتعليم تعاوني وورش عمل وأساليب لعب أدوار . وقد أثنارت نتائج البحث إلى استفادة البحث من معظم نتائج البحوث الدراسات السابقة بوجه عام كمحور إعداد برامج في مهارات المدافعة البيئية مثل: (Baily:1971)

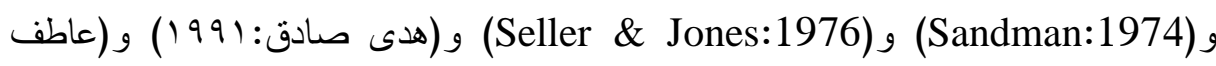


العبد:1991) و (سوزان القلليني:1994) و (ماجدة عامر:؛و199) و (دراسة اتحاد الإذاعة

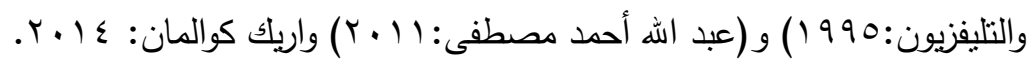

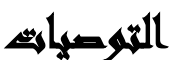

في إطار ما أسفرت عنه نتائج البحث، يوصي الباحث بما يلي: الاستعانة بالبرنامج المقترح وتطبيقه على القائمين بالبرامج الإذاعية لتفعيل دورهم في لبي لئي

المدافعة البيئية.

الاهتمام بمهارات المدافعة البيئية من خلال برامج علمية ممنهجة مخصصة لبعض القطاعات المرتمة بالمدافعة البيئية. مواجهة المشكلات البيئية التي نظهر باستراتيجيات ومهارات المدافعة البيئية.

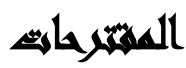

$$
\text { يقترح البحث ما يلي: }
$$

إعداد برامج لتنمية مهارات المدافعة البيئية لبعض الفئات ذات الصلة بالبيئة والثأن

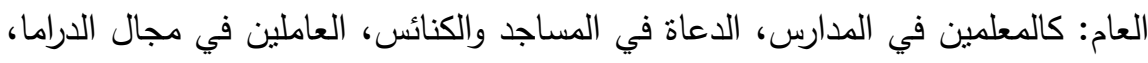

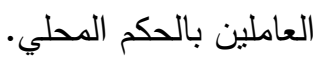

إعداد برامج لتتمية مهارات جديدة للمدافعة البيئية للارتقاء وتطوير طرق حل المشكلات

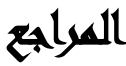

إبراهيم عصدت مطاوع: التربية البيئية في الوطن العربي، طا، (القاهرة، دار الفكر، 990 ())،

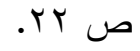

اتحاد الإذاعة والتلافزيون: دور الإذاعة والتليفزيون في التصدي للمشكلات الاجتماعية المعاصرة، بحث غير منشور، القاهرة (الإتحاد، أكتوبر 990 (1) ).

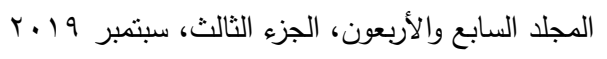


أريك كوالمان: الجدوى الاقتصادية لوسائل الإعلام الاجتماعي، (الرياض، مكتبة جرير،

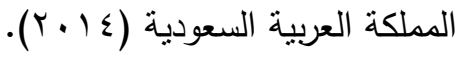

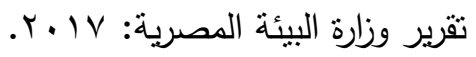

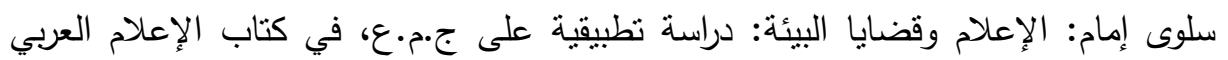

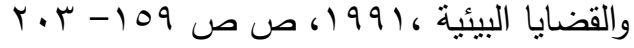

سوزان القليني: التليفزيون وتتمية الوعي البيئي لدى الطفل، في مجلة بحوث الاتصال،

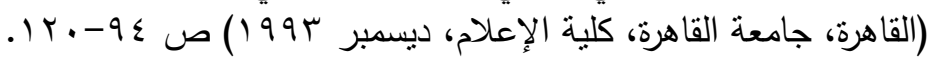

عبد الله أحمد مصطفى: فاعلية برنامج في التربية البيئية في اكساب تلاميذ الحلقة الثانية من دمانية

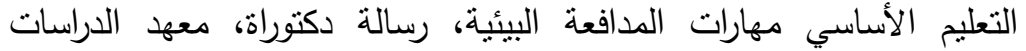

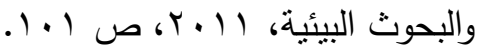

مصطفى كمال طلبة: الحفاظ على البيئة مسئولية قومية وإنسانية، مجلة النيل، العدد.ع،

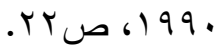

محمد محمود الحيلة: التصميم التعليمي، ط'، (عمّان، دار المسيرة، 999 ())، ص ص برىب.r人o

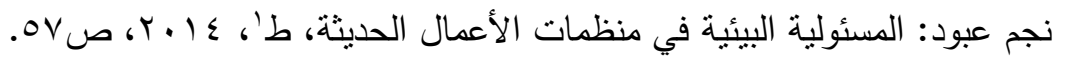

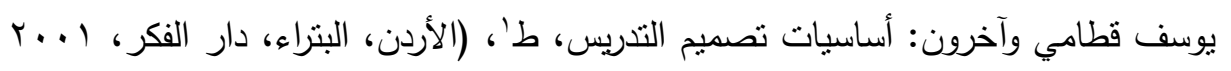

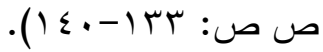

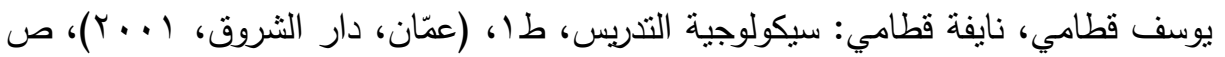

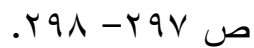

يوسف مرزوق: المدخل إلى حرفية الفن الإذاعي، (القاهرة، مكتبة الأنجلو المصرية، هVو ())، ص ص

African Network of Environmental Journalist https://web.archive.org/web/20130919073257/http://ww w.anej.info/drupal/

Andrew Patrick, B. A.: Climate Change Advocacy and Ecological Modernization: The Symbolic Politics of Carbon Tax Communication in British Columbia Carleton University, April, 2013, Chapter 2. 


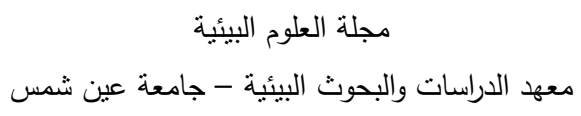

Bailey. G. A.: The Public, The Media and Knowledge Job. Journal of Environmental Education, Vol. 2, 1971, No. 4, p. 3-6

Bunyan Bryant: Instrument Values of Destruction: The Need for Environmental Education. The Race Poverty Environmental Urban Habitat, A Journal for Social and Environmental Justice, 2008.

Dick de Jong: Advocacy for Water, Environmental Sanitation and Hygiene, 2003, P. 4.

Edward A. Johnson and Michael J.: Mapping: Environmental Education and advocacy: Changing Perspectives of Ecology and Education. Cambridge University, 2010, p. 21, ISBN: 0521112397

James E. Crowfoot and Bryant JR.: Environmental Advocacy: An Action Strategy for Dealing with Environmental Problems, Journal of Environmental Education, 1980, p.36

Judy Z. Segal :1991

Lisa M. Pohlman B. A.: Women Leaders of Environmental Advocacy Organizations, A Qualitative Study. December, 2013, pp.21-22. Ph.D. University of Southern Maine.

Sandman, P. M.: An Environmental Education, Can the Media do the job? In Games A Swan \& William B Stapp (Editors), Environmental Education John Wiley \& Sons New York, 1974, pp. 12-33

Seller, L. and Jones, D.: Environment and the mass media in a review of Research related to environmental Education 1976.

Steve Chase (2006): Career Guidance in Environmental Advocacy, Steve Chase directs the master's program in Environmental Advocacy and Organizing at Antioch New England Graduate School.

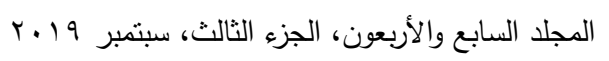


THE DEVELOPMENT OF SOME ENVIRONMENTAL ADVOCACY SKILLS FOR THE PROGRAMMERS IN

\title{
THE EGYPTIAN RADIO
}

\section{Emad A. Abdel Aziz ${ }^{(1)}$; Mahmoud H. Ismail ${ }^{(2)}$ and Reham R. Abdel Aal ${ }^{(3)}$}

1) Egyptian Radio 2) Higher College of Childhood, Ain Shams University 3) Institute of Environmental Studies and Research, Ain Shams University

\begin{abstract}
This research aims to identify and determine the effectiveness of the training program set to develop the skills of environmental advocacy in an experimental group of members of the Egyptian radio programmers. The research study tools are: An environmental note card, and a multi-activity environmental training program. The researcher identified three dimensions for the scale of environmental skills based on previous studies and questionnaires.

The statistical analysis of the results of the skills scale showed the validity of hypotheses and the positive impact of the training program on the development of environmental advocacy skills.
\end{abstract}

